TecnoHumanismo. Revista Científica

https://tecnohumanismo.online

Noviembre 2021

Volumen 1 / No. 11

ISSN: $2710-2394$

pp. $86-108$

https://tecnohumanismo.online

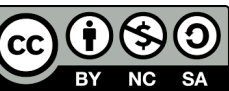

\title{
Competencias y empleabilidad del profesional contable de la universidad nacional de Cajamarca sede Chota
}

Competences and employability of the accounting professional of the national university of Cajamarca headquarters Chota

Competências e empregabilidade do profissional de contabilidade da universidade nacional de Cajamarca sede Chota

ARTÍCULO GENERAL

Lita Elvira Saldaña Dávila

lielsada18@gmail.com

https://orcid.org/0000-0001-8688-9522

Universidad Nacional de Cajamarca

Recibido 18 de Octubre 2021 | Arbitrado y aceptado 18 de Octubre 2021 | Publicado en 08 Noviembre 2021

\section{RESUMEN}

El artículo tuvo como objetivo general demostrar la relación entre las competencias contables adquiridas en la formación profesional y la empleabilidad en el mercado laboral de los egresados de Contabilidad de la Universidad Nacional de Cajamarca sede Chota 2010 - 2015; en tanto, sus objetivos específicos: identificar las competencias contables adquiridas en la formación profesional de los estudiantes de ciencias contables de la Universidad Nacional de Cajamarca, analizar el grado de empleabilidad que mantienen los egresados de la carrera profesional de Contabilidad e identificar las competencias contables adquiridas profesionalmente y su relación con las requeridas en el mercado laboral. Para ello, se usó un cuestionario de 89 ítems en escala de Likert, se aplicó la T de Student y el coeficiente de Spearman; determinando la no significancia estadística entre las competencias desarrolladas en la formación profesional y las requeridas por el mercado laboral, la importancia para la profesión y futuro profesional, sus valores fueron mayores a 0.05; de las 34 secciones evaluadas, solo el $44 \%$ tuvo significancia estadística, y el $56 \%$ no fue significativo; las competencias generales desarrolladas y evaluadas por los jefes no tuvieron significancia estadística, su valor fue 0.0891 , de igual manera las competencias utilizadas en el trabajo no demostraron significancia pues su valor fue 0.999 , las necesarias para la profesión en el futuro 0.877, las competencias para la empleabilidad no son significativas, su valor fue 0.88 .

Palabras clave: Cajamarca, competencias, contabilidad, empleabilidad, universidad nacional.

\section{ABSTRACT}

The general objective of the article was to demonstrate the relationship between the accounting skills acquired in professional training and the employability in the labor market of Accounting graduates from the National University of Cajamarca, Chota headquarters 2010 - 2015; meanwhile, its specific objectives: identify the accounting skills acquired in the professional training of accounting science students at the National University of Cajamarca, analyze the degree of employability maintained by graduates of the accounting professional career and identify the accounting skills acquired professionally and its relationship with those required in the labor market. For this, a questionnaire of 89 items on a Likert scale was used, Student's t and Spearman's coefficient were applied; determining the statistical non-significance between the competencies developed in professional training and those required by the labor market, the importance for the profession and future professional, their values were greater than 0.05 ; of the 34 sections evaluated, only $44 \%$ had statistical significance, and $56 \%$ were not significant; the general competencies developed and evaluated by the bosses did not have statistical significance, their value was 0.0891 , in the same way the competences used at work did not demonstrate significance because their value was 0.999 , those necessary for the profession in the future 0.877, the competences for employability are not significant, its value was 0.88 .

Keywords: Cajamarca, skills, accounting, employability, national university.

\section{RESUMO}

O objetivo geral do artigo foi demonstrar a relação entre as competências contábeis adquiridas na formação profissional e a empregabilidade no mercado de trabalho de graduados em Ciências Contábeis pela Universidade Nacional de Cajamarca, sede Chota 2010 - 2015; entretanto, seus objetivos específicos: identificar as competências contábeis adquiridas na formação profissional dos alunos de ciências contábeis da Universidade Nacional de Cajamarca, analisar o grau de empregabilidade mantido pelos egressos da carreira profissional contábil e identificar as competências contábeis adquiridas profissionalmente e sua relação com as exigidas no mercado de trabalho. Para isso, foi utilizado um questionário de 89 itens em escala Likert, aplicado o coeficiente $\mathrm{t}$ de Student e o coeficiente de Spearman; determinando a não significância estatística entre as competências desenvolvidas na formação profissional e as exigidas pelo mercado de trabalho, a importância para a profissão e futuro profissional, os seus valores foram superiores a 0,05 ; das 34 seções avaliadas, apenas $44 \%$ tiveram significância estatística e $56 \%$ não foram significativas; as competências gerais desenvolvidas e avaliadas pelos chefes não tiveram significância estatística, seu valor foi de 0,0891, da mesma forma que as competências utilizadas no trabalho não demonstraram significância porque seu valor foi de 0,999 , as necessárias para a profissão no futuro 0,877 , o as competências para empregabilidade não são significativas, seu valor foi de 0,88 .

Palavras-chave: Cajamarca, habilidades, contabilidade, universidade nacional. 


\section{Introducción}

El artículo se propuso determinar la relación entre las competencias contables adquiridas en la formación profesional y su empleabilidad en el mercado laboral, siendo las competencias un grupo de capacidades para "aplicar resultados del aprendizaje en un determinado contexto" (Centro de Investigación para el Desarrollo, 2014, p.7). En el mundo globalizado se requiere desarrollar competencias para incrementar la competitividad, a través del capital humano (Aguilar, 2013).

Se buscó que se conozcan las competencias contables de los egresados de contabilidad de la Universidad Nacional de Cajamarca para usarse como base en las universidades tal y como manifiesta el Gobierno de los Estados Unidos de México (2013) y aportar a una educación de calidad. La contabilidad requiere adaptarse siguiendo una enseñanza basada en normas contables y generación de competencias (Castañeda, 2017).

El estudio se basó en las competencias generales abordadas en el Manual de Pronunciamientos Internacionales de Formación del Consejo de Normas Internacionales de Educación Contable (IAESB), de la Federación Internacional de Contadores (IFAC), y empleabilidad abordada por la Organización Internacional del Trabajo (OIT).

\section{Metodología}

Fue cuantitativa, descriptiva, correlacional (Hernández et al. 2014). El análisis fue con SPSS v.22, el modelo de la T de Student y el coeficiente de Spearman. La población fue de 90 egresados de contabilidad, entre varones y mujeres del 2010 al 2015 de la Universidad Nacional de Cajamarca sede Chota. La muestra fue de 90 egresados.

\section{Tabla 1.}

Población de egresados según lugar de trabajo

\begin{tabular}{lllll}
\hline & Sexo & & & \\
Lugar de trabajo & Masculino & Femenino & Total & $\%$ \\
\hline Ente público & 20 & 10 & 29 & 32 \\
Ente privado & 40 & 20 & 61 & 68 \\
Total & 60 & 30 & 90 & 100 \\
\hline
\end{tabular}

Se aplicó un cuestionario a los egresados trabajadores de un ente (1 año o más), para saber qué hacen para desarrollar sus competencias, sus problemas, y cómo se sienten desde su primer trabajo; se aplicó a los empleadores para conocer las competencias que 
los empleados demuestran, y las que necesita el mercado actualmente. La validez del cuestionario fue con el alfa de Cronbach (0.951). Se dividió en 89 ítems, competencias genéricas: 29, competencias específicas 9 dimensiones y 40 ítems y empleabilidad 5 dimensiones y 20 ítems. La prueba piloto consistió en aplicarlo a a 32 estudiantes.

\section{Resultados y discusión}

Se encontró que los egresados laboraban un 32.2\% en un ente público, y el $67.8 \%$ en uno privado, de estos, el $7.8 \%$ son bachilleres, el $83.3 \%$, son titulados y el $8.9 \%$ son magíster.

\section{Tabla 2.}

Tipo de organización laboral y grado académico de los egresados de contabilidad de la Universidad Nacional de Cajamarca sede Chota 2010 - 2015

\begin{tabular}{|c|c|c|c|c|c|c|c|c|c|c|c|}
\hline \multirow{3}{*}{$\begin{array}{c}\text { Tipo de } \\
\text { organización }\end{array}$} & \multicolumn{9}{|c|}{ Grado académico } & & \\
\hline & \multicolumn{2}{|c|}{ Bachiller } & \multicolumn{2}{|c|}{ Titulado } & \multicolumn{2}{|c|}{ Magíster } & \multicolumn{3}{|c|}{ Doctor } & \multicolumn{2}{|c|}{ TOTAL } \\
\hline & $\mathrm{N}^{\circ}$ & $\%$ & $\mathrm{~N}^{\circ}$ & $\%$ & $\mathrm{~N}^{\circ}$ & $\%$ & $\mathrm{~N}^{\circ}$ & $\%$ & & $\mathrm{~N}^{\circ}$ & $\%$ \\
\hline Pública & 2 & 28.6 & 23 , & 30.7 & 4 & 50 & & & 0 & 29 & 32.2 \\
\hline Privada & 5 & 71.4 & 52 , & 69.3 & 4 & 50 & & & 0 & 61 & 67.8 \\
\hline Total $(n=90)$ & 7 & 100 & 75 & 100 & 8 & 100 & & & 0 & 90 & 100 \\
\hline
\end{tabular}

Un $76.7 \%$ de los egresados son subordinados; $23.3 \%$ son jefes y/o gerentes.

\section{Tabla 3.}

Tipo de puesto según grado académico alcanzado de los egresados de la Universidad Nacional de Cajamarca sede Chota 2010 - 2015

\begin{tabular}{|c|c|c|c|c|c|c|c|c|c|c|}
\hline \multirow[b]{3}{*}{ Cargo } & \multicolumn{8}{|c|}{ Grado académico } & & \\
\hline & \multicolumn{2}{|c|}{ Bachiller } & \multicolumn{2}{|c|}{ Titulado } & \multicolumn{2}{|c|}{ Magíster } & \multicolumn{2}{|c|}{ Doctor } & \multicolumn{2}{|c|}{ TOTAL } \\
\hline & $\mathrm{N}^{\circ}$ & $\%$ & $\mathrm{~N}^{\circ}$ & $\%$ & $\mathrm{~N}^{\circ}$ & $\%$ & $\mathrm{~N}^{\circ}$ & $\%$ & $\mathrm{~N}^{\circ}$ & $\%$ \\
\hline Subordinado & 7 & 100.0 & 57 & 80.0 & 5 & 62.5 & 0 & 0 & 69 & 76.7 \\
\hline Gerente & 0 & 0 & 18 & 20.0 & 3 & 37.5 & 0 & 0 & 21 & 23.3 \\
\hline Total $(n=90)$ & 7 & 100.0 & $75^{\circ}$ & 100 & 8 & 100 & 0 & 0 & 90 & 100 \\
\hline
\end{tabular}


Tabla 4.

Población de egresados según grupo de edad y sexo

\begin{tabular}{lllll}
\hline & SEXO & & & \\
Grupo etáreo & Masculino & Femenino & Total & $\%$ \\
\hline $24-26$ & 11 & 5 & 16 & 17.8 \\
$27-29$ & 20 & 10 & 30 & 33.3 \\
$30-32$ & 24 & 12 & 36 & 40.0 \\
$33-35$ & 3 & 2 & 5 & 5.6 \\
$36-37$ & 2 & 1 & 3 & 3.3 \\
Total & 60 & 30 & 90 & 100 \\
\hline
\end{tabular}

Fuente: Cuestionario de investigación 2019.

Las edades de los egresados van entre 24 a 37 años, concentrándose un $40 \%$ entre los de 30 a 32 , y con un $33.3 \%$ los de 27 a 29 años.

Tabla 5.

Población de egresados según lugar de trabajo

\begin{tabular}{lllll} 
LUGAR DE TRABAJO DE EGRESADOS & $\mathrm{N}^{\circ}$ & $\%$ & Acumulado & $\%$ Acumulado \\
\hline Mi Banco & 11 & $12 \%$ & 11 & $12 \%$ \\
UNACH & 10 & $11 \%$ & 21 & $23 \%$ \\
Caja Trujillo & 5 & $6 \%$ & 26 & $29 \%$ \\
CIMAC Piura & 5 & $6 \%$ & 31 & $34 \%$ \\
Banco Continental & 5 & $6 \%$ & 36 & $40 \%$ \\
Cooperativa Todos los Santos de Chota & 4 & $4 \%$ & 40 & $44 \%$ \\
Hospital José Soto Cadenillas & 4 & $4 \%$ & 44 & $49 \%$ \\
Instituto Superior Tecnológico Chota & 4 & $4 \%$ & 48 & $53 \%$ \\
Financiera Confianza & 4 & $4 \%$ & 52 & $58 \%$ \\
Banco de la Nación & 3 & $3 \%$ & 55 & $61 \%$ \\
Municipalidad de Chota & 3 & $3 \%$ & 58 & $64 \%$ \\
Banco de Crédito & 3 & $3 \%$ & 61 & $68 \%$ \\
Corporación hermanos Tapia & 3 & $3 \%$ & 64 & $71 \%$ \\
Credinka S.A. & 3 & $3 \%$ & 67 & $74 \%$ \\
Palmandina SAC & 2 & $2 \%$ & 69 & $77 \%$ \\
EDPYME Alternativa & 2 & $2 \%$ & 71 & $79 \%$ \\
DISA CHOTA & 2 & $2 \%$ & 73 & $81 \%$ \\
Corporación KAUSAY & 2 & $2 \%$ & 75 & $83 \%$ \\
SUNARP & 1 & $1 \%$ & 76 & $84 \%$ \\
Multiservicios Jhan & 1 & $1 \%$ & 77 & $86 \%$ \\
Consorcio Guevara Alarcón & 1 & $1 \%$ & 78 & $87 \%$ \\
Alternativas contables & 1 & $1 \%$ & 79 & $88 \%$ \\
Ministerio de la producción & 1 & $1 \%$ & 80 & $89 \%$ \\
Securgrama SRL Municipalidad Yauyucan & 1 & $1 \%$ & 81 & $90 \%$ \\
Asociación Polvos Grau Lima & 1 & $1 \%$ & 82 & $91 \%$ \\
Gerencia Sub Regional Chota & 1 & $1 \%$ & 83 & $92 \%$ \\
Estudio Contable Chota & 1 & $1 \%$ & 84 & $93 \%$ \\
FAIBICT GROUP SAC & 1 & $1 \%$ & 85 & $94 \%$ \\
Estudio Contable Bambamarca & 1 & $1 \%$ & 86 & $96 \%$ \\
Grifos Burga & 1 & $1 \%$ & 87 & $97 \%$ \\
IE. Negropampa & 1 & $1 \%$ & 88 & $98 \%$ \\
COOPAC NSR & 1 & $1 \%$ & 89 & $99 \%$ \\
Estudio Ramírez & 1 & $1 \%$ & 90 & $100 \%$ \\
\hline & & & &
\end{tabular}

Fuente: Cuestionario de investigación 2019. 
Los egresados laboran en organizaciones públicas como privada, solo un $15 \%$ tiene una organización propia, el 85\% labora en ambos.

\section{Tabla 6.}

Población de jefes según grupo de edad y sexo

\begin{tabular}{lllll}
\hline $\begin{array}{l}\text { Grupo de } \\
\text { Edad }\end{array}$ & SEXO & & & \\
\hline $28-33$ & Masculino & Femenino & Total & $\%$ \\
$34-39$ & 12 & 3 & 15 & 38.5 \\
$40-45$ & 7 & 2 & 9 & 23.1 \\
$46-51$ & 6 & 1 & 7 & 17.9 \\
$52-57$ & 1 & 0 & 1 & 2.6 \\
$58-63$ & 2 & 1 & 3 & 7.7 \\
Total & 3 & 1 & 4 & 10.3 \\
\hline
\end{tabular}

Fuente: cuestionario de investigación 2019.

Las edades de los jefes van de 28 a 63, la mayor frecuencia fue $38.5 \%$ del grupo de 28 a 33 , un $23.1 \%$ de los de 34 a 39; $17.9 \%$ los de 40 a 45 y $10.3 \%$ los de 58 a 63.

\section{Tabla 7.}

Grado académico de jefes según lugar de trabajo

\begin{tabular}{|c|c|c|c|c|}
\hline \multirow[t]{2}{*}{ Grado Académico } & \multicolumn{2}{|c|}{ Tipo de organización } & \multirow[t]{2}{*}{ TOTAL } & \multirow[t]{2}{*}{$\%$} \\
\hline & Pública & Privada & & \\
\hline Doctor & 2 & 0 & 2 & 5.1 \\
\hline Magíster & 5 & 2 & 7 & 17.9 \\
\hline Titulado & 9 & 20 & 29 & 74.4 \\
\hline Bachiller & 0 & 1 & 1 & 2.6 \\
\hline Total & 16 & 23 & 39 & 100.0 \\
\hline
\end{tabular}

Fuente: cuestionario 2019

La tabla 7 indicó que los jefes son titulados en un 74.4\%, el 17.9\% tienen el grado de magíster, el $5.1 \%$ tienen el grado de doctor y solo el 2.6\% es bachiller. El cuestionario se dividió en: Competencias generales (29 items); Competencias específicas (39 items); Empleabilidad (22 items). Tuvo 3 columnas con 4 alternativas en escala de Likert.

\section{Tabla 8.}

Grado de confiabilidad de los cuestionarios

\begin{tabular}{lll}
\hline & \multicolumn{2}{l}{ Alfa de Cronbach } \\
Cuestionario & Egresados & Jefes \\
\hline Universidad & 0.951 & 0.984 \\
Trabajo & 0.972 & 0.961 \\
Profesión & 0.959 & 0.971 \\
Empleabilidad & 0.917 & 0.93 \\
\hline
\end{tabular}

Fuente: cuestionario 2019. 
Tabla 9.

Prueba T por secciones: muestras emparejadas

\begin{tabular}{|c|c|c|c|}
\hline \multicolumn{2}{|r|}{ Secciones del cuestionario } & \multirow{2}{*}{$\frac{\text { Media }}{23.511}$} & \multirow{2}{*}{$\begin{array}{c}\begin{array}{c}\text { Signif. } \\
\text { Bilateral }\end{array} \\
0.000\end{array}$} \\
\hline $\begin{array}{l}\text { Par } 1 \\
\end{array}$ & Total universidad egresados - total universidad jefes & & \\
\hline 1Par 2 & Total trabajo egresados - total trabajo jefes & 6.756 & 0.096 \\
\hline Par 3 & Total profesión egresados - total profesión jefes & -2.367 & 0.567 \\
\hline Par 4 & Total empleabilidad egresados - total empleabilidad jefes & 4.233 & 0.003 \\
\hline 2 Par 5 & Genéricas universidad egresados - genéricas universidad jefes & 9.600 & 0.000 \\
\hline Par 6 & genéricas trabajo egresados - genéricas trabajo jefes & 4.278 & 0.008 \\
\hline Par 7 & Genéricas profesión egresados - genéricas profesión jefes & -1.800 & 0.272 \\
\hline Par 8 & A universidad egresados - A universidad jefes & 2.244 & 0.000 \\
\hline Par 9 & A trabajo egresados - A trabajo jefes & 0.222 & 0.651 \\
\hline Par 10 & A profesión egresados - A profesión jefes & 0.233 & 0.620 \\
\hline Par 11 & B universidad egresados - B universidad jefes & 1.844 & 0.000 \\
\hline Par 12 & $\mathrm{~B}$ trabajo egresados - $\mathrm{B}$ trabajo jefes & 1.033 & 0.036 \\
\hline Par 13 & B profesión egresados - B profesión jefes & 0.267 & 0.539 \\
\hline Par 14 & $\mathrm{C}$ universidad egresados - $\mathrm{C}$ universidad jefes & 2.289 & 0.000 \\
\hline Par 15 & $\mathrm{C}$ trabajo egresados $-\mathrm{C}$ trabajo jefes & 1.211 & 0.052 \\
\hline Par 16 & C profesión egresados - C profesión jefes & 0.422 & 0.440 \\
\hline Par 17 & D universidad egresados - D universidad jefes & 1.344 & 0.000 \\
\hline Par 18 & $\mathrm{D}$ trabajo egresados - D trabajo jefes & 0.267 & 0.551 \\
\hline Par 19 & D profesión egresados - D profesión jefes & 0.356 & 0.385 \\
\hline Par 20 & E universidad egresados - E universidad jefes & 1.056 & 0.000 \\
\hline Par 21 & E trabajo egresados - E trabajo jefes & 0.233 & 0.324 \\
\hline Par 22 & E profesión egresados - E profesión jefes & 0.189 & 0.311 \\
\hline Par 23 & $\mathrm{~F}$ universidad egresados - $\mathrm{F}$ universidad jefes & 1.222 & 0.000 \\
\hline Par 24 & $\mathrm{~F}$ trabajo egresados - $\mathrm{F}$ trabajo jefes & 0.111 & 0.735 \\
\hline Par 25 & F profesión egresados - F profesión jefes & -0.389 & 0.147 \\
\hline Par 26 & G universidad egresados - $\mathrm{G}$ universidad jefes & 0.844 & 0.016 \\
\hline Par 27 & G trabajo egresados - $\mathrm{G}$ trabajo jefes & -0.322 & 0.368 \\
\hline Par 28 & G profesión egresados - G profesión jefes & -0.722 & 0.046 \\
\hline Par 29 & $\mathrm{H}$ universidad egresados - $\mathrm{H}$ universidad jefes & 1.356 & 0.000 \\
\hline Par 30 & $\mathrm{H}$ trabajo egresados - $\mathrm{H}$ trabajo jefes & 0.022 & 0.951 \\
\hline Par 31 & H profesión egresados - H profesión jefes & -0.289 & 0.333 \\
\hline Par 32 & I universidad egresados - I universidad jefes & 1.711 & 0.000 \\
\hline Par 33 & i trabajo egresados - $\mathrm{i}$ trabajo jefes & -0.300 & 0.490 \\
\hline Par 34 & i profesión egresados - i profesión jefes & -0.633 & 0.133 \\
\hline
\end{tabular}

Fuente: cuestionario 2019.

Solo 15 secciones tienen diferencia significativa. La opinión de los egresados tiene un valor de 0.000 . Pero en el uso de competencias en el trabajo y la importancia para su profesión en el futuro, no hay difrencia significativa. 
Tabla 10.

\section{Prueba T por items de competencias logradas en la universidad, evaluadas por egresados y jefes}

Competencia genéricas y específicas

Significancia

bilateral

\begin{tabular}{llll}
\hline Par 1 & Poseo capacidad de abstracción, análisis y síntesis. - Poseo capacidad de abstracción, análisis y & 0.027
\end{tabular} síntesis.

Par 2 Poseo capacidad de aprender y actualizarme permanentemente - Poseo capacidad de aprender y

0.001 actualizarme permanentemente

Par 3 Tengo conocimientos sobre el área de estudio y la profesión - Tengo conocimientos sobre el área 0.001 de estudio y la profesión

Par 4 Poseo Capacidad para identificar, plantear y resolver problemas - Poseo Capacidad para

0.000 identificar, plantear y resolver problemas

Par 5 Tengo capacidad de investigación - Tengo capacidad de investigación

Par 6 Poseo habilidades en el uso de las tecnologías de la información y de la comunicación. - Poseo habilidades en el uso de las tecnologías de la información y de la comunicación.

Par 7 Poseo Habilidad para recolectar y procesar información - Poseo Habilidad para recolectar y procesar información

Par 8 Poseo habilidad para analizar información - Poseo habilidad para analizar información

Par 9 Tengo capacidad de comunicación oral - Tengo capacidad de comunicación oral

Par 10 Tengo capacidad de comunicación escrita - Tengo capacidad de comunicación escrita

Par 11 Tengo capacidad de aplicar los conocimientos en la práctica - Tengo capacidad de aplicar los conocimientos en la práctica

Par 12 Demuestro Compromiso con mi medio sociocultural - Demuestro Compromiso con mi medio sociocultural

Par 13 Demuestro valoración y respeto por la diversidad y multiculturalidad - Demuestro valoración y respeto por la diversidad y multiculturalidad

Par 14 Demuestro responsabilidad social y compromiso ciudadano - Demuestro responsabilidad social y compromiso ciudadano

Par 15 Demuestro Compromiso con la preservación del medio ambiente - Demuestro Compromiso con la preservación del medio ambiente

Par 16 Demuestro compromiso con la calidad - Demuestro compromiso con la calidad 0.002

Par 17 Demuestro compromiso ético - Demuestro compromiso ético 0.000

Par 18 Tengo capacidad de comunicación en un segundo idioma - Tengo capacidad de comunicación en $\quad 0.288$ un segundo idioma

Par 19 Tengo habilidad para trabajar en contextos internacionales - Tengo habilidad para trabajar en contextos internacionales

$\begin{array}{lll}\text { Par } 20 & \text { Poseo habilidades interpersonales - Poseo habilidades interpersonales } & 0.008\end{array}$

Par 21 Poseo capacidad para tomar decisiones - Poseo capacidad para tomar decisiones 0.000

Par 22 Poseo capacidad para motivar y conducir hacia metas comunes - Poseo capacidad para motivar y 0.000 conducir hacia metas comunes

Par 23 Poseo capacidad de trabajo en equipo - Poseo capacidad de trabajo en equipo 0.000

Par 24 Poseo capacidad para organizar y planificar el tiempo - Poseo capacidad para organizar y $\quad 0.003$ planificar el tiempo

Par 25 Poseo capacidad para actuar en nuevas situaciones - Poseo capacidad para actuar en nuevas 0.001 situaciones

Par 26 Poseo habilidad para trabajar en forma autónoma - Poseo habilidad para trabajar en forma 0.001 autónoma

Par 27 Poseo capacidad para formular y gestionar proyectos - Poseo capacidad para formular y 0.005 gestionar proyectos

$\begin{array}{lll}\text { Par } 28 & \text { Poseo capacidad crítica y autocrítica - Poseo capacidad crítica y autocrítica } & 0.088\end{array}$

Par 29 Poseo capacidad creativa - Poseo capacidad creativa 0.000

$\begin{array}{lll}\text { Par } 30 & \text { Aplico principios contables a transacciones y otros eventos. - Aplico principios contables a } & 0.000\end{array}$ transacciones y otros eventos.

Par 31 Aplico las Normas Internacionales de Información Financiera a transacciones y otros eventos. Aplico las Normas Internacionales de Información Financiera a transacciones y otros eventos.

Par 32 Elaboro estados financieros en base a normas contables (NIIF) - Elaboro estados financieros en base a normas contables (NIIF)

Par 33 Interpreto estados financieros y revelaciones correspondientes - Interpreto estados financieros y revelaciones correspondientes 
Par 34 Interpreto informes que incluyan datos no financieros (Informes de sustentabilidad e integrados)

0.001 - Interpreto informes que incluyan datos no financieros (Informes de sustentabilidad e integrados)

Par 35 Tomo decisiones de dirección incluyendo costos de productos, análisis de variaciones, gestión de 0.004 inventarios, presupuestos y proyecciones. - Tomo decisiones de dirección incluyendo costos de productos, análisis de variaciones, gestión de inventarios, presupuestos y proyecciones.

Par 36 Aplico técnicas cuantitativas apropiadas para analizar el comportamiento de los costos y sus generadores. - Aplico técnicas cuantitativas apropiadas para analizar el comportamiento de los costos y sus generadores.

Par 37 Analizo información financiera y no financiera relevante para proporcionar a la dirección para tomar decisiones. - Aplico técnicas cuantitativas apropiadas para analizar el comportamiento de los costos y sus generadores.

Par 38 Evalúo los informes elaborados para tomar decisiones. - Evalúo los informes elaborados para tomar decisiones.

Par 39 Evalúo el desempeño de productos y segmentos del negocio. - Evalúo el desempeño de productos y segmentos del negocio.

Par 40 Identifico fuentes de financiamiento para mi organización incluyendo financiamiento bancario, bonos, tesorería, mercados de capitales. - Identifico fuentes de financiamiento para mi organización incluyendo financiamiento bancario, bonos, tesorería, mercados de capitales.

Par 41 Analizo el flujo de efectivo de mi organización y los requerimientos de capital de trabajo. Analizo el flujo de efectivo de mi organización y los requerimientos de capital de trabajo.

Par 42 Analizo la situación financiera actual y futura de la organización mediante razones financieras, tendencias y flujos de efectivo. - Analizo la situación financiera actual y futura de la organización mediante razones financieras, tendencias y flujos de efectivo.

Par 43 Conozco como evaluar el costo de capital de mi organización - Conozco como evaluar el costo de capital de mi organización

Par 44 Utilizo técnicas financieras para las decisiones de inversión de capital de una organización. Utilizo técnicas financieras para las decisiones de inversión de capital de una organización.

Par 45 Conozco los componentes financieros para la planeación financiera y gestión de negocios a largo plazo. - Conozco los componentes financieros para la planeación financiera y gestión de negocios a largo plazo.

Par 46 Explico los requisitos de cumplimiento y presentación de impuestos de acuerdo a normas SUNAT - Explico los requisitos de cumplimiento y presentación de impuestos de acuerdo a normas SUNAT

Par 47 Realizo el cálculo de impuestos de personas y organizaciones. - Realizo el cálculo de impuestos de personas y organizaciones.

Par 48 Realizo cálculos de impuestos de transacciones internacionales - Realizo cálculos de impuestos de transacciones internacionales

Par 49 Conozco las diferencias entre planeación de impuestos, elusión de impuestos y evasión de impuestos. - Conozco las diferencias entre planeación de impuestos, elusión de impuestos y evasión de impuestos.

Par 50 Conozco y describo las etapas para desarrollar una auditoria de estados financieros - Conozco y describo las etapas para desarrollar una auditoria de estados financieros

Par 51 Conozco, aplico métodos y normas de auditoría contable - Conozco, aplico métodos y normas de auditoría contable

Par 52 Conozco los principios de un buen gobierno corporativo, incluyendo derechos y responsabilidades de propietarios, inversionistas, interesados y requerimientos de transparencia. - Conozco los principios de un buen gobierno corporativo, incluyendo derechos y responsabilidades de propietarios, inversionistas, interesados y requerimientos de transparencia.

Par 53 Analizo los riesgos y oportunidades de una organización - Analizo los riesgos y oportunidades de una organización

Par 54 Conozco y aplico el proceso de control interno relacionado a la información financiera. Conozco y aplico el proceso de control interno relacionado a la información financiera.

Par 55 Conozco las leyes y regulaciones que controlan las diferentes formas de entidades legales. Conozco las leyes y regulaciones que controlan las diferentes formas de entidades legales.

Par 56 Explico las leyes y regulaciones aplicables a la contabilidad. - Explico las leyes y regulaciones aplicables a la contabilidad.

Par 57 Describo el entorno político, legal, social, medio ambiental, económico y ambiental en el que actúa una entidad. - Describo el entorno político, legal, social, medio ambiental, económico y ambiental en el que actúa una entidad.

Par 58 Identifico las características de la globalización incluyendo el rol de mercados multinacionales, comercio electrónico y mercados emergentes. - Identifico las características de la globalización incluyendo el rol de mercados multinacionales, comercio electrónico y mercados emergentes.

Par 59 Describo los principios fundamentales de la micro y macro economía. - Describo los principios fundamentales de la micro y macro economía. 
Par 60 Describo los efectos de los indicadores macroeconómicos sobre la actividad del negocio. -

Describo los efectos de los indicadores macroeconómicos sobre la actividad del negocio.

Par 61 Conozco las diversas estructuras de mercado como: Competencia perfecta, monopólica, monopolio y oligopolio. - Conozco las diversas estructuras de mercado como: Competencia perfecta, monopólica, monopolio y oligopolio.

Par 62 Conozco las diversas formas de diseño y organización empresarial. - Conozco las diversas formas de diseño y organización empresarial.

Par 63 Conozco el propósito e importancia de las diferentes áreas funcionales de una organización. Conozco el propósito e importancia de las diferentes áreas funcionales de una organización.

Par 64 Conozco como diseñar una estrategia organizacional - Conozco como diseñar una estrategia organizacional

Par 65 Conozco el proceso para implementar una estrategia - Conozco el proceso para implementar una 0.000 estrategia

Par 66 Conozco teorías y puedo utilizarlo para mejorar el desempeño de individuos, equipo y organización. - Conozco teorías y puedo utilizarlo para mejorar el desempeño de individuos, equipo y organización.

Fuente: Cuestionario 2019.

Del total, 58 ítems tienen diferencia significativa en relación al valor expresado por los egresados y jefes, 8 ítems no tienen significanacia estadística. Ello indica que no hay coherencia con lo dicho por IFAC y lo desarrollado en el profesional en estudio.

\section{Tabla 11.}

\section{Prueba T por items de competencias según grado de importancia para la profesión}

\begin{tabular}{|c|c|c|}
\hline Ítem & Competencias genéricas y específicas & Sig.(bilateral) \\
\hline Par 1 & $\begin{array}{l}\text { Poseo capacidad de abstracción, análisis y síntesis. - Poseo capacidad de abstracción, análisis y } \\
\text { síntesis. }\end{array}$ & 0.335 \\
\hline Par 2 & $\begin{array}{l}\text { Poseo capacidad de aprender y actualizarme permanentemente - Poseo capacidad de aprender y } \\
\text { actualizarme permanentemente }\end{array}$ & 0.247 \\
\hline Par 3 & $\begin{array}{l}\text { Tengo conocimientos sobre el área de estudio y la profesión - Tengo conocimientos sobre el } \\
\text { área de estudio y la profesión }\end{array}$ & 0.030 \\
\hline Par 4 & $\begin{array}{l}\text { Poseo Capacidad para identificar, plantear y resolver problemas - Poseo Capacidad para } \\
\text { identificar, plantear y resolver problemas }\end{array}$ & 0.720 \\
\hline Par 5 & Tengo capacidad de investigación - Tengo capacidad de investigación & 0.556 \\
\hline Par 6 & $\begin{array}{l}\text { Poseo habilidades en el uso de las tecnologías de la información y de la comunicación. - Poseo } \\
\text { habilidades en el uso de las tecnologías de la información y de la comunicación. }\end{array}$ & 0.235 \\
\hline Par 7 & $\begin{array}{l}\text { Poseo Habilidad para recolectar y procesar información - Poseo Habilidad para recolectar y } \\
\text { procesar información }\end{array}$ & 0.150 \\
\hline Par 8 & Poseo habilidad para analizar información - Poseo habilidad para analizar información & 0.532 \\
\hline Par 9 & Tengo capacidad de comunicación oral - Tengo capacidad de comunicación oral & 0.807 \\
\hline Par 10 & Tengo capacidad de comunicación escrita - Tengo capacidad de comunicación escrita & 0.167 \\
\hline Par 11 & $\begin{array}{l}\text { Tengo capacidad de aplicar los conocimientos en la práctica - Tengo capacidad de aplicar los } \\
\text { conocimientos en la práctica }\end{array}$ & 0.132 \\
\hline Par 12 & $\begin{array}{l}\text { Demuestro Compromiso con mi medio sociocultural - Demuestro Compromiso con mi medio } \\
\text { sociocultural }\end{array}$ & 0.381 \\
\hline Par 13 & $\begin{array}{l}\text { Demuestro valoración y respeto por la diversidad y multiculturalidad - Demuestro valoración y } \\
\text { respeto por la diversidad y multiculturalidad }\end{array}$ & 0.045 \\
\hline Par 14 & $\begin{array}{l}\text { Demuestro responsabilidad social y compromiso ciudadano - Demuestro responsabilidad social } \\
\text { y compromiso ciudadano }\end{array}$ & 0.198 \\
\hline Par 15 & $\begin{array}{l}\text { Demuestro Compromiso con la preservación del medio ambiente - Demuestro Compromiso con } \\
\text { la preservación del medio ambiente }\end{array}$ & 0.911 \\
\hline Par 16 & Demuestro compromiso con la calidad - Demuestro compromiso con la calidad & 0.795 \\
\hline Par 17 & Demuestro compromiso ético - Demuestro compromiso ético & 0.574 \\
\hline Par 18 & $\begin{array}{l}\text { Tengo capacidad de comunicación en un segundo idioma - Tengo capacidad de comunicación } \\
\text { en un segundo idioma }\end{array}$ & 0.377 \\
\hline Par 19 & $\begin{array}{l}\text { Tengo habilidad para trabajar en contextos internacionales - Tengo habilidad para trabajar en } \\
\text { contextos internacionales }\end{array}$ & 0.165 \\
\hline
\end{tabular}




\begin{tabular}{|c|c|}
\hline Ittem & Competencias genéricas y específicas \\
\hline Par 20 & Poseo habilidades interpersonales - Poseo habilidades interpersonales \\
\hline Par 21 & Poseo capacidad para tomar decisiones - Poseo capacidad para tomar decisiones \\
\hline Par 22 & $\begin{array}{l}\text { Poseo capacidad para motivar y conducir hacia metas comunes - Poseo capacidad para moti } \\
\text { y conducir hacia metas comunes }\end{array}$ \\
\hline Par 23 & Poseo capacidad de trabajo en equipo - Poseo capacidad de trabajo en equipo \\
\hline Par 24 & $\begin{array}{l}\text { Poseo capacidad para organizar y planificar el tiempo - Poseo capacidad para organizar y } \\
\text { planificar el tiempo }\end{array}$ \\
\hline Par 25 & $\begin{array}{l}\text { Poseo capacidad para actuar en nuevas situaciones - Poseo capacidad para actuar en nuevas } \\
\text { situaciones }\end{array}$ \\
\hline Par 26 & $\begin{array}{l}\text { Poseo habilidad para trabajar en forma autónoma - Poseo habilidad para trabajar en forma } \\
\text { autónoma }\end{array}$ \\
\hline Par 27 & $\begin{array}{l}\text { Poseo capacidad para formular y gestionar proyectos - Poseo capacidad para formular y } \\
\text { gestionar proyectos }\end{array}$ \\
\hline Par 28 & Poseo capacidad crítica y autocrítica - Poseo capacidad crítica y autocrítica \\
\hline Par 29 & Poseo capacidad creativa - Poseo capacidad creativa \\
\hline Par 30 & $\begin{array}{l}\text { Aplico principios contables a transacciones y otros eventos. - Aplico principios contables a } \\
\text { transacciones y otros eventos. }\end{array}$ \\
\hline
\end{tabular}

Par 31 Aplico las Normas Internacionales de Información Financiera a transacciones y otros eventos. Aplico las Normas Internacionales de Información Financiera a transacciones y otros eventos.

Par 32 Elaboro estados financieros en base a normas contables (NIIF) - Elaboro estados financieros en base a normas contables (NIIF)

Par 33 Interpreto estados financieros y revelaciones correspondientes - Interpreto estados financieros y revelaciones correspondientes

Interpreto informes que incluyan datos no financieros (Informes de sustentabilidad e integrados)

Par 34 - Interpreto informes que incluyan datos no financieros (Informes de sustentabilidad e integrados)

Tomo decisiones de dirección incluyendo costos de productos, análisis de variaciones, gestión

Par 35 de inventarios, presupuestos y proyecciones. - Tomo decisiones de dirección incluyendo costos de productos, análisis de variaciones, gestión de inventarios, presupuestos y proyecciones.

Aplico técnicas cuantitativas apropiadas para analizar el comportamiento de los costos y sus

Par 36 generadores. - Aplico técnicas cuantitativas apropiadas para analizar el comportamiento de los costos y sus generadores.

Analizo información financiera y no financiera relevante para proporcionar a la dirección para

Par 37 tomar decisiones. - Aplico técnicas cuantitativas apropiadas para analizar el comportamiento de los costos y sus generadores.

Par 38 Evalúo los informes elaborados para tomar decisiones. - Evalúo los informes elaborados para tomar decisiones.

Par 39 Evalúo el desempeño de productos y segmentos del negocio. - Evalúo el desempeño de productos y segmentos del negocio.

Identifico fuentes de financiamiento para mi organización incluyendo financiamiento bancario,

Par 40 bonos, tesorería, mercados de capitales. - Identifico fuentes de financiamiento para mi organización incluyendo financiamiento bancario, bonos, tesorería, mercados de capitales.

Par 41 Analizo el flujo de efectivo de mi organización y los requerimientos de capital de trabajo. Analizo el flujo de efectivo de mi organización y los requerimientos de capital de trabajo. Analizo la situación financiera actual y futura de la organización mediante razones financieras,

Par 42 tendencias y flujos de efectivo. - Analizo la situación financiera actual y futura de la organización mediante razones financieras, tendencias y flujos de efectivo.

Par 43 Conozco como evaluar el costo de capital de mi organización - Conozco como evaluar el costo de capital de mi organización

Par 44 Utilizo técnicas financieras para las decisiones de inversión de capital de una organización. Utilizo técnicas financieras para las decisiones de inversión de capital de una organización. Conozco los componentes financieros para la planeación financiera y gestión de negocios a

Par 45 largo plazo. - Conozco los componentes financieros para la planeación financiera y gestión de negocios a largo plazo.

Explico los requisitos de cumplimiento y presentación de impuestos de acuerdo a normas

Par 46 SUNAT - Explico los requisitos de cumplimiento y presentación de impuestos de acuerdo a normas SUNAT

Par 47 Realizo el cálculo de impuestos de personas y organizaciones. - Realizo el cálculo de impuestos

Par 47 Realizo el cálculo de impuestos de personas y organizaciones. - Realizo el cálculo de impuestos

Par 48 Realizo cálculos de impuestos de transacciones internacionales - Realizo cálculos de impuestos de transacciones internacionales

Conozco las diferencias entre planeación de impuestos, elusión de impuestos y evasión de

Par 49 impuestos. - Conozco las diferencias entre planeación de impuestos, elusión de impuestos y evasión de impuestos.

Par 50 Conozco y describo las etapas para desarrollar una auditoria de estados financieros - Conozco y describo las etapas para desarrollar una auditoria de estados financieros 


\begin{tabular}{|c|c|c|}
\hline Ítem & Competencias genéricas y específicas & Sig.(bilateral) \\
\hline Par 51 & $\begin{array}{l}\text { Conozco, aplico métodos y normas de auditoría contable - Conozco, aplico métodos y normas } \\
\text { de auditoría contable }\end{array}$ & 1.000 \\
\hline Par 52 & $\begin{array}{l}\text { Conozco los principios de un buen gobierno corporativo, incluyendo derechos y } \\
\text { responsabilidades de propietarios, inversionistas, interesados y requerimientos de transparencia. } \\
\text { - Conozco los principios de un buen gobierno corporativo, incluyendo derechos y } \\
\text { responsabilidades de propietarios, inversionistas, interesados y requerimientos de transparencia. }\end{array}$ & 0.034 \\
\hline Par 53 & $\begin{array}{l}\text { Analizo los riesgos y oportunidades de una organización - Analizo los riesgos y oportunidades } \\
\text { de una organización }\end{array}$ & 0.561 \\
\hline Par 54 & $\begin{array}{l}\text { Conozco y aplico el proceso de control interno relacionado a la información financiera. - } \\
\text { Conozco y aplico el proceso de control interno relacionado a la información financiera. }\end{array}$ & 0.305 \\
\hline Par 55 & $\begin{array}{l}\text { Conozco las leyes y regulaciones que controlan las diferentes formas de entidades legales. - } \\
\text { Conozco las leyes y regulaciones que controlan las diferentes formas de entidades legales. }\end{array}$ & 0.081 \\
\hline Par 56 & $\begin{array}{l}\text { Explico las leyes y regulaciones aplicables a la contabilidad. - Explico las leyes y regulaciones } \\
\text { aplicables a la contabilidad. }\end{array}$ & 0.078 \\
\hline Par 57 & $\begin{array}{l}\text { Describo el entorno político, legal, social, medio ambiental, económico y ambiental en el que } \\
\text { actúa una entidad. - Describo el entorno político, legal, social, medio ambiental, económico y } \\
\text { ambiental en el que actúa una entidad. }\end{array}$ & 0.184 \\
\hline Par 58 & $\begin{array}{l}\text { Identifico las características de la globalización incluyendo el rol de mercados multinacionales, } \\
\text { comercio electrónico y mercados emergentes. - Identifico las características de la globalización } \\
\text { incluyendo el rol de mercados multinacionales, comercio electrónico y mercados emergentes. }\end{array}$ & 0.098 \\
\hline Par 59 & $\begin{array}{l}\text { Describo los principios fundamentales de la micro y macro economía. - Describo los principios } \\
\text { fundamentales de la micro y macro economía. }\end{array}$ & 0.300 \\
\hline Par 60 & $\begin{array}{l}\text { Describo los efectos de los indicadores macroeconómicos sobre la actividad del negocio. - } \\
\text { Describo los efectos de los indicadores macroeconómicos sobre la actividad del negocio. }\end{array}$ & 0.256 \\
\hline Par 61 & $\begin{array}{l}\text { Conozco las diversas estructuras de mercado como: Competencia perfecta, monopólica, } \\
\text { monopolio y oligopolio. - Conozco las diversas estructuras de mercado como: Competencia } \\
\text { perfecta, monopólica, monopolio y oligopolio. }\end{array}$ & 0.603 \\
\hline Par 62 & $\begin{array}{l}\text { Conozco las diversas formas de diseño y organización empresarial. - Conozco las diversas } \\
\text { formas de diseño y organización empresarial. }\end{array}$ & 0.735 \\
\hline Par 63 & $\begin{array}{l}\text { Conozco el propósito e importancia de las diferentes áreas funcionales de una organización. - } \\
\text { Conozco el propósito e importancia de las diferentes áreas funcionales de una organización. }\end{array}$ & 0.109 \\
\hline Par 64 & $\begin{array}{l}\text { Conozco como diseñar una estrategia organizacional - Conozco como diseñar una estrategia } \\
\text { organizacional }\end{array}$ & 0.234 \\
\hline Par 65 & $\begin{array}{l}\text { Conozco el proceso para implementar una estrategia - Conozco el proceso para implementar una } \\
\text { estrategia }\end{array}$ & 0.139 \\
\hline Par 66 & $\begin{array}{l}\text { Conozco teorías y puedo utilizarlo para mejorar el desempeño de individuos, equipo y } \\
\text { organización. - Conozco teorías y puedo utilizarlo para mejorar el desempeño de individuos, } \\
\text { equipo y organización. }\end{array}$ & 0.071 \\
\hline
\end{tabular}

Fuente: Cuestionario 2019.

Solo un $4.5 \%$ muestran significancia entre lo manifestado por jefes y egresados, demostrando que las competencias no son las necesarias en el mercado laboral. Como manifiesta la Federación Internacional de Contadores (2008) estos deben tener competencias para desempeñarse en su campo de estudios y según los resultados, los jefes no están de acuerdo con sus competencias en los diversas tareas encomendadas.

Tabla 12.

\section{Prueba T por items de competencias de empleabilidad egresados vs jefes}

\begin{tabular}{llc}
\hline Ítem & Competencias de empleabilidad & $\begin{array}{c}\text { Sig. } \\
\text { (bilateral) }\end{array}$ \\
\hline Par 1 & $\begin{array}{l}\text { Realizo todas las tareas de mi puesto de trabajo sin dificultad alguna - Realizo todas las tareas } \\
\text { de mi puesto de trabajo sin dificultad alguna }\end{array}$ & 0.483 \\
Par 2 & $\begin{array}{l}\text { Mantengo gran aceptación en mi trabajo por la práctica de valores. - Mantengo gran } \\
\text { aceptación en mi trabajo por la práctica de valores. }\end{array}$ & 0.596
\end{tabular}
aceptación en mi trabajo por la práctica de valores. 
Par 3 Soluciono todo problema relacionado con mi trabajo - Soluciono todo problema relacionado

0.012 con mi trabajo

Par 4 Soy capaz de trabajar en coordinación con todas las áreas de mi institución. - Soy capaz de 0.003 trabajar en coordinación con todas las áreas de mi institución.

Par 5 Poseo formación empresarial suficiente - Poseo formación empresarial suficiente

Par 6 Soy capaz de generar mi autoempleo - Soy capaz de generar mi autoempleo

Par 7 Busco adquirir nuevos conocimientos - Busco adquirir nuevos conocimientos

0.000

Par 8 Soy capaz de implementar nuevos procesos para mejorar mi trabajo. - Soy capaz de

0.002 implementar nuevos procesos para mejorar mi trabajo.

Par 9 Me adecuo a los cambios en mi trabajo de forma rápida - Me adecuo a los cambios en mi 0.001 trabajo de forma rápida

Par 10 Mantengo comunicación laboral para mejorar, a través, de medios informáticos. - Mantengo comunicación laboral para mejorar, a través, de medios informáticos.

Par 11 Soy capaz de fijar mis metas laborales por encima del estándar - Soy capaz de fijar mis metas 0.000 laborales por encima del estándar

Par 12 Cumplo mis metas laborales establecidas con éxito - Cumplo mis metas laborales establecidas 0.019 con éxito

Par 13 Las ofertas del mercado laboral para mi profesión son suficientes - Las ofertas del mercado laboral para mi profesión son suficientes

Par 14 Las exigencias de los empleadores son difíciles de cumplir - Las exigencias de los empleadores son difíciles de cumplir

Par 15 Mi desempeño es en un puesto correspondiente a mi profesión - Mi desempeño es en un puesto correspondiente a mi profesión

Par 16 El sueldo es muy atractivo de acuerdo a mis expectativas - El sueldo es muy atractivo de acuerdo a mis expectativas

Par 17 Estoy muy satisfecho en mi trabajo por las oportunidades brindadas. - Estoy muy satisfecho en 0.003 mi trabajo por las oportunidades brindadas.

Par 18 Tengo excelente estado de salud físico - Tengo excelente estado de salud físico 0.365

Par 19 Mi estado de salud psicológico es muy bueno - Mi estado de salud psicológico es muy bueno 0.061

Par 20 El medio de transporte a mi trabajo es muy accesible - El medio de transporte a mi trabajo es 0.301 muy accesible

Par 21 Mis ingresos me permiten cubrir todas mis necesidades económicas - Mis ingresos me permiten cubrir todas mis necesidades económicas

Par 22 Mi asistencia al trabajo es al 100\%, nunca me ausento sin motivo - Mi asistencia al trabajo es 0.006 al $100 \%$, nunca me ausento sin motivo

\section{Fuente: Cuestionario 2019.}

La prueba T demostró que las competencias de empleabilidad por los jefes y egresados no tiene significancia estadística al 100\%. Mimbredo et al. (2016) dijo que los egresados de la UNC deben superar barreras de empleabilidad en el mercado laboral.

Tabla 13.

Correlaciones generales mediante el Rho de Spearman

\begin{tabular}{|c|c|c|c|c|}
\hline \multirow{7}{*}{$\begin{array}{l}\text { Rho de } \\
\text { Spearman }\end{array}$} & \multirow{3}{*}{$\begin{array}{l}\text { Total universidad } \\
\text { egresados }\end{array}$} & & $\begin{array}{l}\text { Total universidad } \\
\text { egresados }\end{array}$ & Total universidad jefes \\
\hline & & $\begin{array}{l}\text { Coeficiente de } \\
\text { correlación }\end{array}$ & 1.000 & -0.015 \\
\hline & & Sig. (bilateral) & & 0.891 \\
\hline & \multirow{4}{*}{ Total universidad jefes } & $\mathrm{N}$ & 90 & 90 \\
\hline & & $\begin{array}{l}\text { Coeficiente de } \\
\text { correlación }\end{array}$ & -0.015 & 1.000 \\
\hline & & Sig. (bilateral) & 0.891 & \\
\hline & & $\mathrm{N}$ & 90 & 90 \\
\hline
\end{tabular}

Fuente: cuestionario 2019 
Tabla 14.

Correlaciones generales mediante el Rho de Spearman

\begin{tabular}{lllll}
\hline Rho de & Total trabajo egresados & Total trabajo egresados & Total trabajo jefes \\
Spearman & & $\begin{array}{l}\text { Coeficiente de } \\
\text { correlación } \\
\text { Sig. (bilateral) }\end{array}$ & 1.000 & 0.000 \\
& & 90 & 0.999 \\
& N & 0.000 & 90 \\
Total trabajo jefes & $\begin{array}{l}\text { Coficiente de } \\
\text { correlación } \\
\text { Sig. (bilateral) }\end{array}$ & 0.999 & 1.000 \\
& & N & 90 & 90 \\
\hline
\end{tabular}

Fuente: cuestionario 2019

\section{Tabla 15.}

Correlaciones generales mediante el Rho de Spearman

\begin{tabular}{lllll}
\hline & & $\begin{array}{l}\text { Total profesión } \\
\text { egresados }\end{array}$ & $\begin{array}{l}\text { Total profesión } \\
\text { jefes }\end{array}$ \\
\hline Rho de & Total profesión egresados & $\begin{array}{l}\text { Coeficiente de } \\
\text { Spearman }\end{array}$ & $\begin{array}{l}\text { correlación } \\
\text { Sig. (bilateral) }\end{array}$ & 0.017 \\
& N & 90 & 0.877 \\
& Total profesión jefes & Coeficiente de & 0.017 & 90 \\
& & & 1.000 \\
& & correlación & \\
& Sig. (bilateral) & 0.877 & \\
& N & 90 & 90 \\
\hline
\end{tabular}

Fuente: cuestionario 2019

Tabla 16.

Correlaciones generales mediante el Rho de Spearman

\begin{tabular}{|c|c|c|c|c|}
\hline & & & $\begin{array}{l}\text { Total empleabilidad } \\
\text { egresados }\end{array}$ & $\begin{array}{l}\text { Total empleabilidad } \\
\text { jefes }\end{array}$ \\
\hline \multirow[t]{6}{*}{$\begin{array}{l}\text { Rho de } \\
\text { Spearman }\end{array}$} & $\begin{array}{l}\text { Total empleabilidad } \\
\text { egresados }\end{array}$ & $\begin{array}{l}\text { Coeficiente de } \\
\text { correlación }\end{array}$ & 1.000 & 0.015 \\
\hline & & Sig. (bilateral) & & 0.887 \\
\hline & & $\mathrm{N}$ & 90 & 90 \\
\hline & Total empleabilidad jefes & $\begin{array}{l}\text { Coeficiente de } \\
\text { correlación }\end{array}$ & 0.015 & 1.000 \\
\hline & & Sig. (bilateral) & 0.887 & \\
\hline & & $\mathrm{N}$ & 90 & 90 \\
\hline
\end{tabular}

Fuente: cuestionario 2019

Las competencias de empleabilidad de los egresados, no son las requeridas por el mercado laboral. La empleabilidad es una competencia para diseñar la carrera profesional, acceder al mercado de trabajo y gestionar el propio desarrollo laboral, e involucra a todos los agentes sociales, principalmente a los de educación y empleadores (Martínez, 2011). 
Tabla 17.

Correlaciones mediante el Rho de Spearman

\begin{tabular}{|c|c|c|c|c|c|c|c|}
\hline Rho de Spearman & & $\begin{array}{l}\text { Genéricas } \\
\text { universidad } \\
\text { egresados }\end{array}$ & $\begin{array}{l}\text { Genéricas } \\
\text { trabajo } \\
\text { egresados }\end{array}$ & $\begin{array}{l}\text { Genéricas } \\
\text { profesión } \\
\text { egresados }\end{array}$ & $\begin{array}{l}\text { Genéricas } \\
\text { universidad } \\
\text { jefes }\end{array}$ & $\begin{array}{l}\text { Genéricas } \\
\text { trabajo } \\
\text { jefes }\end{array}$ & $\begin{array}{l}\text { genéricas } \\
\text { profesión } \\
\text { jefes }\end{array}$ \\
\hline \multirow{3}{*}{$\begin{array}{l}\text { Genéricas } \\
\text { universidad } \\
\text { egresados }\end{array}$} & $\begin{array}{l}\text { Coeficiente de } \\
\text { correlación }\end{array}$ & 1.000 & ,445 &, 341 & -0.085 & -0.083 & -0.030 \\
\hline & Sig. (bilateral) & & 0.000 & 0.001 & 0.426 & 0.437 & 0.781 \\
\hline & $\mathrm{N}$ & 90 & 90 & 90 & 90 & 90 & 90 \\
\hline \multirow{3}{*}{$\begin{array}{l}\text { Genéricas } \\
\text { trabajo } \\
\text { egresados }\end{array}$} & $\begin{array}{l}\text { Coeficiente de } \\
\text { correlación }\end{array}$ & ,445 & 1.000 &, 775 & 0.006 & -0.027 & 0.006 \\
\hline & Sig. (bilateral) & 0.000 & & 0.000 & 0.953 & 0.800 & 0.952 \\
\hline & $\mathrm{N}$ & 90 & 90 & 90 & 90 & 90 & $90 \mathrm{mo}$ \\
\hline \multirow{3}{*}{$\begin{array}{l}\text { Genéricas } \\
\text { profesión } \\
\text { egresados }\end{array}$} & $\begin{array}{l}\text { Coeficiente de } \\
\text { correlación }\end{array}$ & ,341 & ,775 & 1.000 & 0.139 & 0.060 & -0.007 \\
\hline & Sig. (bilateral) & 0.001 & 0.000 & & 0.190 & 0.574 & 0.945 \\
\hline & $\mathrm{N}$ & 90 & 90 & 90 & 90 & 90 & 90 \\
\hline \multirow{3}{*}{$\begin{array}{l}\text { Genéricas } \\
\text { universidad } \\
\text { jefes }\end{array}$} & $\begin{array}{l}\text { Coeficiente de } \\
\text { correlación }\end{array}$ & -0.085 & 0.006 & 0.139 & 1.000 &, 586 & 0.055 \\
\hline & Sig. (bilateral) & 0.426 & 0.953 & 0.190 & & 0.000 & 0.609 \\
\hline & $\mathrm{N}$ & 90 & 90 & 90 & 90 & 90 & 90 \\
\hline \multirow[t]{3}{*}{$\begin{array}{l}\text { Genéricas } \\
\text { trabajo jefes }\end{array}$} & $\begin{array}{l}\text { Coeficiente de } \\
\text { correlación }\end{array}$ & -0.083 & -0.027 & 0.060 & ,586 & 1.000 & ,319 \\
\hline & Sig. (bilateral) & 0.437 & 0.800 & 0.574 & 0.000 & & 0.002 \\
\hline & $\mathrm{N}$ & 90 & 90 & 90 & 90 & 90 & 90 \\
\hline \multirow[t]{3}{*}{$\begin{array}{l}\text { Genéricas } \\
\text { profesión jefes }\end{array}$} & $\begin{array}{l}\text { Coeficiente de } \\
\text { correlación }\end{array}$ & -0.030 & 0.006 & -0.007 & 0.055 & ,319 & 1.000 \\
\hline & Sig. (bilateral) & 0.781 & 0.952 & 0.945 & 0.609 & 0.002 & \\
\hline & $\mathrm{N}$ & 90 & 90 & 90 & 90 & 90 & 90 \\
\hline
\end{tabular}

Fuente: cuestionario 2019

\section{La diferencia establecida para egresados y jefes no es significativa, en cuanto a} competencias adquiridas en la universidad, utilizadas en el trabajo y necesarias para la carrera profesional, siendo sus valores: $0.426,0.800$ y 0.945 respectivamente.

Tabla 18.

Correlaciones mediante el Rho de Spearman

\begin{tabular}{|c|c|c|c|c|c|c|c|c|}
\hline \multicolumn{3}{|c|}{ Conceptos } & \multirow{2}{*}{$\begin{array}{l}\text { Auniversidad } \\
\text { egresados }\end{array}$} & \multirow{2}{*}{$\begin{array}{l}\begin{array}{l}\text { A trabajo } \\
\text { egresados }\end{array} \\
, 295^{* *}\end{array}$} & \multirow{2}{*}{$\begin{array}{l}\begin{array}{l}\text { Aprofesión } \\
\text { egresados }\end{array} \\
, 396^{* *}\end{array}$} & \multirow{2}{*}{$\begin{array}{l}\begin{array}{l}\text { Auniversi } \\
\text { dad jefes }\end{array} \\
-0.032\end{array}$} & \multirow{2}{*}{$\begin{array}{l}\text { Atrabaj } \\
\text { o jefes } \\
-0.022\end{array}$} & \multirow{2}{*}{$\begin{array}{l}\text { A profesión } \\
\text { jefes } \\
-0.026\end{array}$} \\
\hline $\begin{array}{l}\text { Rho } \\
\text { de }\end{array}$ & $\begin{array}{l}\text { A } \\
\text { universidad }\end{array}$ & $\begin{array}{l}\text { Coeficiente de } \\
\text { correlación }\end{array}$ & & & & & & \\
\hline Spear & egresados & Sig. (bilateral) & & 0.005 & 0.000 & 0.766 & 0.835 & 0.805 \\
\hline \multirow[t]{8}{*}{ man } & & $\mathrm{N}$ & 90 & 90 & 90 & 90 & 90 & 90 \\
\hline & $\begin{array}{l}\text { A trabajo } \\
\text { egresados }\end{array}$ & $\begin{array}{l}\text { Coeficiente de } \\
\text { correlación }\end{array}$ &, $295 * *$ & 1.000 &, $542 * *$ & -0.090 & 0.032 & 0.001 \\
\hline & & Sig. (bilateral) & 0.005 & & 0.000 & 0.401 & 0.761 & 0.990 \\
\hline & & $\mathrm{N}$ & 90 & 90 & 90 & 90 & 90 & 90 \\
\hline & $\begin{array}{l}\text { A profesión } \\
\text { egresados }\end{array}$ & $\begin{array}{l}\text { Coeficiente de } \\
\text { correlación }\end{array}$ &, $396 * *$ &, $542 * *$ & 1.000 & -0.023 & -0.069 & -0.005 \\
\hline & & Sig. (bilateral) & 0.000 & 0.000 & & 0.833 & 0.519 & 0.965 \\
\hline & & $\mathrm{N}$ & 90 & 90 & 90 & 90 & 90 & 90 \\
\hline & & $\begin{array}{l}\text { Coeficiente de } \\
\text { correlación }\end{array}$ & -0.032 & -0.090 & -0.023 & 1.000 &, $590 * *$ &, $511 * *$ \\
\hline
\end{tabular}




\begin{tabular}{|c|c|c|c|c|c|c|c|}
\hline A & Sig. (bilateral) & 0.766 & 0.401 & 0.833 & & 0.000 & 0.000 \\
\hline $\begin{array}{l}\text { universidad } \\
\text { jefes }\end{array}$ & $\mathrm{N}$ & 90 & 90 & 90 & 90 & 90 & 90 \\
\hline \multirow[t]{3}{*}{$\begin{array}{l}\text { A trabajo } \\
\text { jefes }\end{array}$} & $\begin{array}{l}\text { Coeficiente de } \\
\text { correlación }\end{array}$ & -0.022 & 0.032 & -0.069 &, $590 * *$ & 1.000 &, $585^{* *}$ \\
\hline & Sig. (bilateral) & 0.835 & 0.761 & 0.519 & 0.000 & & 0.000 \\
\hline & $\mathrm{N}$ & 90 & 90 & 90 & 90 & 90 & 90 \\
\hline \multirow[t]{3}{*}{$\begin{array}{l}\text { A profesión } \\
\text { jefes }\end{array}$} & $\begin{array}{l}\text { Coeficiente de } \\
\text { correlación }\end{array}$ & -0.026 & 0.001 & -0.005 &, $511 * *$ &, $585^{* *}$ & 1.000 \\
\hline & Sig. (bilateral) & 0.805 & 0.990 & 0.965 & 0.000 & 0.000 & \\
\hline & $\mathrm{N}$ & 90 & 90 & 90 & 90 & 90 & 90 \\
\hline
\end{tabular}

Fuente: cuestionario 2019

La significancia estadística de los puntajes de egresados sobre Contabilidad e información financiera aprendida en la universidad y su uso en el trabajo y útil para la profesión es significativa, pero no para los jefes. Los valores de egresados para la misma competencia utilizada en el trabajo tienen significancia para egresados, pero no para los jefes $(0.766,0.761$ y 0.965$)$. Igualmente, el puntaje de los egresados en tal competencia para la profesión en el futuro es significativa más no con los jefes $(0.833$, 0.519 y 0.965$)$.

\section{Tabla 19.}

Correlaciones mediante el Coeficiente de Pearson

\begin{tabular}{|c|c|c|c|c|c|c|c|}
\hline \multicolumn{2}{|c|}{ Evaluación y valores } & $\begin{array}{l}\text { Buniversida } \\
\text { d egresados }\end{array}$ & $\begin{array}{l}\text { B trabajo } \\
\text { egresados }\end{array}$ & $\begin{array}{l}\text { B profesión } \\
\text { egresados }\end{array}$ & $\begin{array}{l}\text { B universidad } \\
\text { jefes }\end{array}$ & $\begin{array}{l}\text { B trabajo } \\
\text { jefes }\end{array}$ & $\begin{array}{l}\text { B profesión } \\
\text { jefes }\end{array}$ \\
\hline \multirow{3}{*}{$\begin{array}{l}\text { B } \\
\text { universidad } \\
\text { egresados }\end{array}$} & $\begin{array}{l}\text { Correlación } \\
\text { de Pearson }\end{array}$ & 1 &, 471 & ,359 & 0.018 & -0.043 & -0.027 \\
\hline & $\begin{array}{l}\text { Sig. } \\
\text { (bilateral) }\end{array}$ & & 0.000 & 0.001 & 0.866 & 0.685 & 0.803 \\
\hline & $\mathrm{N}$ & 90 & 90 & 90 & 90 & 90 & 90 \\
\hline \multirow[t]{3}{*}{$\begin{array}{l}\text { B trabajo } \\
\text { egresados }\end{array}$} & $\begin{array}{l}\text { Correlación } \\
\text { de Pearson }\end{array}$ &, 471 & 1 & ,624 & -0.014 & -0.091 & 0.011 \\
\hline & $\begin{array}{l}\text { Sig. } \\
\text { (bilateral) }\end{array}$ & 0.000 & & 0.000 & 0.897 & 0.394 & 0.917 \\
\hline & $\mathrm{N}$ & 90 & 90 & 90 & 90 & 90 & 90 \\
\hline \multirow[t]{3}{*}{$\begin{array}{l}\text { B profesión } \\
\text { egresados }\end{array}$} & $\begin{array}{l}\text { Correlación } \\
\text { de Pearson }\end{array}$ & ,359 & ,624 & 1 & 0.108 & -0.048 & 0.066 \\
\hline & $\begin{array}{l}\text { Sig. } \\
\text { (bilateral) }\end{array}$ & 0.001 & 0.000 & & 0.312 & 0.651 & 0.537 \\
\hline & $\mathrm{N}$ & 90 & 90 & 90 & 90 & 90 & 90 \\
\hline \multirow{3}{*}{$\begin{array}{l}\text { B } \\
\text { universidad } \\
\text { jefes }\end{array}$} & $\begin{array}{l}\text { Correlación } \\
\text { de Pearson }\end{array}$ & 0.018 & -0.014 & 0.108 & 1 & ,496 &, 363 \\
\hline & $\begin{array}{l}\text { Sig. } \\
\text { (bilateral) }\end{array}$ & 0.866 & 0.897 & 0.312 & & 0.000 & 0.000 \\
\hline & $\mathrm{N}$ & 90 & 90 & 90 & 90 & 90 & 90 \\
\hline \multirow[t]{3}{*}{$\begin{array}{l}\text { B trabajo } \\
\text { jefes }\end{array}$} & $\begin{array}{l}\text { Correlación } \\
\text { de Pearson }\end{array}$ & -0.043 & -0.091 & -0.048 & ,496 & 1 & ,465 \\
\hline & $\begin{array}{l}\text { Sig. } \\
\text { (bilateral) }\end{array}$ & 0.685 & 0.394 & 0.651 & 0.000 & & 0.000 \\
\hline & $\mathrm{N}$ & 90 & 90 & 90 & 90 & 90 & 90 \\
\hline \multirow[t]{3}{*}{$\begin{array}{l}\text { B profesión } \\
\text { jefes }\end{array}$} & $\begin{array}{l}\text { Correlación } \\
\text { de Pearson }\end{array}$ & -0.027 & 0.011 & 0.066 & ,363 & ,465 & 1 \\
\hline & $\begin{array}{l}\text { Sig. } \\
\text { (bilateral) }\end{array}$ & 0.803 & 0.917 & 0.537 & 0.000 & 0.000 & \\
\hline & $\mathrm{N}$ & 90 & 90 & 90 & 90 & 90 & 90 \\
\hline
\end{tabular}


Fuente: cuestionario 2019

No hay significancia entre valores de Contabilidad Administrativa de los egresados para la competencia adquirida en la universidad, usada en el trabajo e importancia para la profesión en el futuro con los jefes $(0.866,0.394$ y 0.537$)$.

Tabla 20.

Correlaciones mediante coeficiente de Pearson

\begin{tabular}{|c|c|c|c|c|c|c|c|}
\hline Conceptos & & $\begin{array}{l}\mathrm{C} \text { universidad } \\
\text { egresados }\end{array}$ & $\begin{array}{l}\mathrm{C} \text { trabajo } \\
\text { egresados }\end{array}$ & $\begin{array}{l}\text { C profesión } \\
\text { egresados }\end{array}$ & $\begin{array}{l}\text { C } \\
\text { universidad } \\
\text { jefes }\end{array}$ & $\begin{array}{l}\text { C } \\
\text { trabajo } \\
\text { jefes }\end{array}$ & $\begin{array}{l}\text { C profesión } \\
\text { jefes }\end{array}$ \\
\hline \multirow{3}{*}{$\begin{array}{l}\mathrm{C} \\
\text { universidad } \\
\text { egresados }\end{array}$} & $\begin{array}{l}\text { Correlación } \\
\text { de Pearson }\end{array}$ & 1 & ,492 & ,449 & 0.025 & 0.019 & 0.040 \\
\hline & Sig. (bilateral) & & 0.000 & 0.000 & 0.818 & 0.860 & 0.707 \\
\hline & $\mathrm{N}$ & 90 & 90 & 90 & 90 & 90 & 90 \\
\hline \multirow[t]{3}{*}{$\begin{array}{l}\mathrm{C} \text { trabajo } \\
\text { egresados }\end{array}$} & $\begin{array}{l}\text { Correlación } \\
\text { de Pearson }\end{array}$ & ,492 & 1 &, 552 & 0.027 & -0.053 & -0.015 \\
\hline & Sig. (bilateral) & 0.000 & & 0.000 & 0.801 & 0.618 & 0.889 \\
\hline & $\mathrm{N}$ & 90 & 90 & 90 & 90 & 90 & 90 \\
\hline \multirow[t]{3}{*}{$\begin{array}{l}\mathrm{C} \text { profesión } \\
\text { egresados }\end{array}$} & $\begin{array}{l}\text { Correlación } \\
\text { de Pearson }\end{array}$ & ,449 &, 552 & 1 & 0.151 & -0.007 & 0.020 \\
\hline & Sig. (bilateral) & 0.000 & 0.000 & & 0.156 & 0.947 & 0.849 \\
\hline & $\mathrm{N}$ & 90 & 90 & 90 & 90 & 90 & 90 \\
\hline \multirow{3}{*}{$\begin{array}{l}\text { C } \\
\text { universidad } \\
\text { jefes }\end{array}$} & $\begin{array}{l}\text { Correlación } \\
\text { de Pearson }\end{array}$ & 0.025 & 0.027 & 0.151 & 1 & ,630 & ,291 \\
\hline & Sig. (bilateral) & 0.818 & 0.801 & 0.156 & & 0.000 & 0.005 \\
\hline & $\mathrm{N}$ & 90 & 90 & 90 & 90 & 90 & 90 \\
\hline \multirow[t]{3}{*}{$\begin{array}{l}\mathrm{C} \text { trabajo } \\
\text { jefes }\end{array}$} & $\begin{array}{l}\text { Correlación } \\
\text { de Pearson }\end{array}$ & 0.019 & -0.053 & -0.007 & ,630 & 1 &, 558 \\
\hline & Sig. (bilateral) & 0.860 & 0.618 & 0.947 & 0.000 & & 0.000 \\
\hline & $\mathrm{N}$ & 90 & 90 & 90 & 90 & 90 & 90 \\
\hline \multirow[t]{3}{*}{$\begin{array}{l}\text { C profesión } \\
\text { jefes }\end{array}$} & $\begin{array}{l}\text { Correlación } \\
\text { de Pearson }\end{array}$ & 0.040 & -0.015 & 0.020 & ,291 &, 558 & 1 \\
\hline & Sig. (bilateral) & 0.707 & 0.889 & 0.849 & 0.005 & 0.000 & \\
\hline & $\mathrm{N}$ & 90 & 90 & 90 & 90 & 90 & 90 \\
\hline
\end{tabular}

Fuente: cuestionario 2019

Existe significancia para finanzas y gestión financiera para los egresados con el valor de 0.000 , pero no entre la competencia aprendida en la universidad por la evaluada por los jefes (sus valores: $0.818,0.618$ y 0.849 ; valores de significancia son $>0.05$ ). 
Tabla 21.

Correlaciones mediante el Coeficiente de Pearson

\begin{tabular}{|c|c|c|c|c|c|c|c|}
\hline ITEM & & $\begin{array}{l}\mathrm{D} \\
\text { universidad } \\
\text { egresados }\end{array}$ & $\begin{array}{l}\mathrm{D} \text { trabajo } \\
\text { egresados }\end{array}$ & $\begin{array}{l}\text { D profesión } \\
\text { egresados }\end{array}$ & $\begin{array}{l}\text { D } \\
\text { universidad } \\
\text { jefes }\end{array}$ & $\begin{array}{l}\text { D trabajo } \\
\text { jefes }\end{array}$ & $\begin{array}{l}\text { D profesión } \\
\text { jefes }\end{array}$ \\
\hline \multirow{3}{*}{$\begin{array}{l}\text { D } \\
\text { universid } \\
\text { ad } \\
\text { egresados }\end{array}$} & $\begin{array}{l}\text { Correlación } \\
\text { de Pearson }\end{array}$ & 1 &, 447 & ,577 & 0.201 &, 251 & 0.195 \\
\hline & Sig. (bilateral) & & 0.000 & 0.000 & 0.057 & 0.017 & 0.065 \\
\hline & $\mathrm{N}$ & 90 & 90 & 90 & 90 & 90 & 90 \\
\hline \multirow[t]{3}{*}{$\begin{array}{l}\text { D trabajo } \\
\text { egresados }\end{array}$} & $\begin{array}{l}\text { Correlación } \\
\text { de Pearson }\end{array}$ &, 447 & 1 & ,600 & -0.054 & 0.054 & -0.006 \\
\hline & Sig. (bilateral) & 0.000 & & 0.000 & 0.614 & 0.615 & 0.957 \\
\hline & $\mathrm{N}$ & 90 & 90 & 90 & 90 & 90 & 90 \\
\hline \multirow{3}{*}{$\begin{array}{l}\text { D } \\
\text { profesión } \\
\text { egresados }\end{array}$} & $\begin{array}{l}\text { Correlación } \\
\text { de Pearson }\end{array}$ &, 577 & ,600 & 1 & -0.011 & -0.088 & 0.035 \\
\hline & Sig. (bilateral) & 0.000 & 0.000 & & 0.915 & 0.407 & 0.745 \\
\hline & $\mathrm{N}$ & 90 & 90 & 90 & 90 & 90 & 90 \\
\hline \multirow{3}{*}{$\begin{array}{l}\mathrm{D} \\
\text { universid } \\
\text { ad jefes }\end{array}$} & $\begin{array}{l}\text { Correlación } \\
\text { de Pearson }\end{array}$ & 0.201 & -0.054 & -0.011 & 1 &, 581 & ,445 \\
\hline & Sig. (bilateral) & 0.057 & 0.614 & 0.915 & & 0.000 & 0.000 \\
\hline & $\mathrm{N}$ & 90 & 90 & 90 & 90 & 90 & 90 \\
\hline \multirow[t]{2}{*}{$\begin{array}{l}\text { D trabajo } \\
\text { jefes }\end{array}$} & $\begin{array}{l}\text { Correlación } \\
\text { de Pearson }\end{array}$ &, 251 & 0.054 & -0.088 &, 581 & 1 & ,453 \\
\hline & Sig. (bilateral) & 0.017 & 0.615 & 0.407 & 0.000 & & 0.000 \\
\hline \multirow{4}{*}{$\begin{array}{l}\text { D } \\
\text { profesión } \\
\text { jefes }\end{array}$} & $\mathrm{N}$ & 90 & 90 & 90 & 90 & 90 & 90 \\
\hline & $\begin{array}{l}\text { Correlación } \\
\text { de Pearson }\end{array}$ & 0.195 & -0.006 & 0.035 & ,445 &, 453 & 1 \\
\hline & Sig. (bilateral) & 0.065 & 0.957 & 0.745 & 0.000 & 0.000 & \\
\hline & $\mathrm{N}$ & 90 & 90 & 90 & 90 & 90 & 90 \\
\hline
\end{tabular}

Fuente: cuestionario 2019

El valor de significancia de los egresados para las competencias en el área de impuestos es significativo para las competencias desarrolladas en la universidad con las utilizadas en el trabajo, profesión y valores por demostrar de 0.000 , sin embargo, no son significativa con la evaluación de los jefes para la universidad, trabajo y profesión en el futuro (valores $0.057,0.615$ y 0.745 ) ello no es compatible con lo dicho por IFAC (2017). 
Tabla 22.

Correlaciones mediante el coeficiente de Pearson

\begin{tabular}{|c|c|c|c|c|c|c|c|}
\hline ITEM & & $\begin{array}{l}\text { E universidad } \\
\text { egresados }\end{array}$ & $\begin{array}{l}\text { E trabajo } \\
\text { egresados }\end{array}$ & $\begin{array}{l}\text { E profesión } \\
\text { egresados }\end{array}$ & $\begin{array}{l}\text { E universidad } \\
\text { jefes }\end{array}$ & $\begin{array}{l}\text { E trabajo } \\
\text { jefes }\end{array}$ & $\begin{array}{l}\text { E profesión } \\
\text { jefes }\end{array}$ \\
\hline \multirow{3}{*}{$\begin{array}{l}\text { E } \\
\text { universidad } \\
\text { egresados }\end{array}$} & $\begin{array}{l}\text { Correlación } \\
\text { de Pearson }\end{array}$ & 1 &, 458 & ,489 &, 226 & 0.176 & 0.110 \\
\hline & $\begin{array}{l}\text { Sig. } \\
\text { (bilateral) }\end{array}$ & & 0.000 & 0.000 & 0.032 & 0.097 & 0.303 \\
\hline & $\mathrm{N}$ & 90 & 90 & 90 & 90 & 90 & 90 \\
\hline \multirow[t]{3}{*}{$\begin{array}{l}\text { E trabajo } \\
\text { egresados }\end{array}$} & $\begin{array}{l}\text { Correlación } \\
\text { de Pearson }\end{array}$ & ,458 & 1 & ,443 & -0.147 & 0.040 & 0.003 \\
\hline & $\begin{array}{l}\text { Sig. } \\
\text { (bilateral) }\end{array}$ & 0.000 & & 0.000 & 0.166 & 0.709 & 0.976 \\
\hline & $\mathrm{N}$ & 90 & 90 & 90 & 90 & 90 & 90 \\
\hline \multirow[t]{3}{*}{$\begin{array}{l}\text { E profesión } \\
\text { egresados }\end{array}$} & $\begin{array}{l}\text { Correlación } \\
\text { de Pearson }\end{array}$ & ,489 & ,443 & 1 & 0.052 & 0.026 & 0.097 \\
\hline & $\begin{array}{l}\text { Sig. } \\
\text { (bilateral) }\end{array}$ & 0.000 & 0.000 & & 0.627 & 0.805 & 0.363 \\
\hline & $\mathrm{N}$ & 90 & 90 & 90 & 90 & 90 & 90 \\
\hline \multirow{3}{*}{$\begin{array}{l}\text { E } \\
\text { universidad } \\
\text { jefes }\end{array}$} & $\begin{array}{l}\text { Correlación } \\
\text { de Pearson }\end{array}$ &, $226 *$ & -0.147 & 0.052 & 1 & ,449 & ,300 \\
\hline & $\begin{array}{l}\text { Sig. } \\
\text { (bilateral) }\end{array}$ & 0.032 & 0.166 & 0.627 & & 0.000 & 0.004 \\
\hline & $\mathrm{N}$ & 90 & 90 & 90 & 90 & 90 & 90 \\
\hline \multirow[t]{3}{*}{$\begin{array}{l}\text { E trabajo } \\
\text { jefes }\end{array}$} & $\begin{array}{l}\text { Correlación } \\
\text { de Pearson }\end{array}$ & 0.176 & 0.040 & 0.026 & ,449 & 1 &, 347 \\
\hline & $\begin{array}{l}\text { Sig. } \\
\text { (bilateral) }\end{array}$ & 0.097 & 0.709 & 0.805 & 0.000 & & 0.001 \\
\hline & $\mathrm{N}$ & 90 & 90 & 90 & 90 & 90 & 90 \\
\hline \multirow[t]{3}{*}{$\begin{array}{l}\text { E profesión } \\
\text { jefes }\end{array}$} & $\begin{array}{l}\text { Correlación } \\
\text { de Pearson }\end{array}$ & 0.110 & 0.003 & 0.097 &, 300 & ,347 & 1 \\
\hline & $\begin{array}{l}\text { Sig. } \\
\text { (bilateral) }\end{array}$ & 0.303 & 0.976 & 0.363 & 0.004 & 0.001 & \\
\hline & $\mathrm{N}$ & 90 & 90 & 90 & 90 & 90 & 90 \\
\hline
\end{tabular}

Fuente: cuestionario 2019

En la competencia específica de auditoría y aseguramiento hay significancia entre los valores de calificación de la competencia de los egresados en la universidad con la competencia para el trabajo, la profesión y con los valores de los jefes para las competencias logradas en la universidad para los egresados, pero no para los jefes. El valor de los egresados para el trabajo y la profesión es significativo para la competencia de los egresados lograda en la universidad y para la profesión, más no para los jefes, (significancia de 0.032 y relación positiva baja de 0.226 ) no demostrando relación alguna para el trabajo y profesión con la evaluación de los jefes, (0.709 y 0.300). 
Tabla 23.

Correlaciones mediante el Coeficiente de Pearson

\begin{tabular}{|c|c|c|c|c|c|c|c|}
\hline & & $\begin{array}{l}\text { F universidad } \\
\text { egresados }\end{array}$ & $\begin{array}{l}\text { F trabajo } \\
\text { egresados }\end{array}$ & $\begin{array}{l}\text { F profesión } \\
\text { egresados }\end{array}$ & $\begin{array}{l}\mathrm{F} \\
\text { universida } \\
\mathrm{d} \text { jefes }\end{array}$ & $\begin{array}{l}\text { F trabajo } \\
\text { jefes }\end{array}$ & $\begin{array}{l}\text { F profesión } \\
\text { jefes }\end{array}$ \\
\hline \multirow[t]{3}{*}{$\begin{array}{l}\text { F universidad } \\
\text { egresados }\end{array}$} & $\begin{array}{l}\text { Correlación de } \\
\text { Pearson }\end{array}$ & 1 & ,429 & ,498 & -0.029 & -0.015 & -0.111 \\
\hline & Sig. (bilateral) & & 0.000 & 0.000 & 0.787 & 0.886 & 0.299 \\
\hline & $\mathrm{N}$ & 90 & 90 & 90 & 90 & 90 & 90 \\
\hline \multirow[t]{3}{*}{$\begin{array}{l}\mathrm{F} \text { trabajo } \\
\text { egresados }\end{array}$} & $\begin{array}{l}\text { Correlación de } \\
\text { Pearson }\end{array}$ & ,429 & 1 & ,587 & -0.180 & -0.152 & -0.100 \\
\hline & Sig. (bilateral) & 0.000 & & 0.000 & 0.089 & 0.152 & 0.346 \\
\hline & $\mathrm{N}$ & 90 & 90 & 90 & 90 & 90 & 90 \\
\hline \multirow[t]{3}{*}{$\begin{array}{l}\text { F profesión } \\
\text { egresados }\end{array}$} & $\begin{array}{l}\text { Correlación de } \\
\text { Pearson }\end{array}$ & ,498 & ,587 & 1 & 0.02741 & -248 & -0.118 \\
\hline & Sig. (bilateral) & 0.000 & 0.000 & & 0.698 & 0.019 & 0.266 \\
\hline & $\mathrm{N}$ & 90 & 90 & 90 & 90 & 90 & 90 \\
\hline \multirow[t]{3}{*}{$\begin{array}{l}\text { F universidad } \\
\text { jefes }\end{array}$} & $\begin{array}{l}\text { Correlación de } \\
\text { Pearson }\end{array}$ & -0.029 & -0.180 & 0.041 & 1 & 0.042 & 0.103 \\
\hline & Sig. (bilateral) & 0.787 & 0.089 & 0.698 & & 0.692 & 0.335 \\
\hline & $\mathrm{N}$ & 90 & 90 & 90 & 90 & 90 & 90 \\
\hline \multirow[t]{3}{*}{$\begin{array}{l}F \text { trabajo } \\
\text { jefes }\end{array}$} & $\begin{array}{l}\text { Correlación de } \\
\text { Pearson }\end{array}$ & -0.015 & -0.152 & -248 & 0.042 & 1 & 0.088 \\
\hline & Sig. (bilateral) & 0.886 & 0.152 & 0.019 & 0.692 & & 0.411 \\
\hline & $\mathrm{N}$ & 90 & 90 & 90 & 90 & 90 & 90 \\
\hline \multirow[t]{3}{*}{$\begin{array}{l}\text { F profesión } \\
\text { jefes }\end{array}$} & $\begin{array}{l}\text { Correlación de } \\
\text { Pearson }\end{array}$ & -0.111 & -0.100 & -0.118 & 0.103 & 0.088 & 1 \\
\hline & Sig. (bilateral) & 0.299 & 0.346 & 0.266 & 0.335 & 0.411 & \\
\hline & $\mathrm{N}$ & 90 & 90 & 90 & 90 & 90 & 90 \\
\hline
\end{tabular}

Fuente: cuestionario 2019

La gestión de riesgo y control son funciones inherentes al profesional contable (Universidad de Chile: Facultad de Economía y Negocios, 2019) competencia que tiene una significancia para los egresados y lo que necesitan para el trabajo, pero no para los jefes sobre las competencias contables desarrolladas en la universidad, para el desarrollo del trabajo y utilidad para la profesión en el futuro $(0.787,0.152$ y 0.266 respectivamente).

Tabla 24.

Correlaciones mediante Coeficiente de Pearson

\begin{tabular}{|c|c|c|c|c|c|c|c|}
\hline & & $\begin{array}{l}\text { G } \\
\text { universidad } \\
\text { egresados }\end{array}$ & $\begin{array}{l}\mathrm{G} \text { trabajo } \\
\text { egresados }\end{array}$ & $\begin{array}{l}\mathrm{G} \\
\text { profesión } \\
\text { egresados }\end{array}$ & $\begin{array}{l}\text { G } \\
\text { universidad } \\
\text { jefes }\end{array}$ & $\begin{array}{l}\text { G } \\
\text { trabajo } \\
\text { jefes }\end{array}$ & $\begin{array}{l}\mathrm{G} \\
\text { profesión } \\
\text { jefes }\end{array}$ \\
\hline \multirow[t]{3}{*}{$\begin{array}{l}\text { G universidad } \\
\text { egresados }\end{array}$} & $\begin{array}{l}\text { Correlación } \\
\text { de Pearson }\end{array}$ & 1 & ,540 & ,577 & 0.093 & 0.055 & -0.033 \\
\hline & $\begin{array}{l}\text { Sig. } \\
\text { (bilateral) }\end{array}$ & & 0.000 & 0.000 & 0.382 & 0.605 & 0.756 \\
\hline & $\mathrm{N}$ & 90 & 90 & 90 & 90 & 90 & 90 \\
\hline \multirow[t]{3}{*}{$\begin{array}{l}\text { G trabajo } \\
\text { egresados }\end{array}$} & $\begin{array}{l}\text { Correlación } \\
\text { de Pearson }\end{array}$ & ,540 & 1 & ,660 & 0.028 & 0.046 & 0.118 \\
\hline & $\begin{array}{l}\text { Sig. } \\
\text { (bilateral) }\end{array}$ & 0.000 & & 0.000 & 0.793 & 0.670 & 0.266 \\
\hline & $\mathrm{N}$ & 90 & 90 & 90 & 90 & 90 & 90 \\
\hline
\end{tabular}




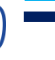

\begin{tabular}{|c|c|c|c|c|c|c|c|}
\hline \multirow[t]{3}{*}{$\begin{array}{l}\text { G profesión } \\
\text { egresados }\end{array}$} & $\begin{array}{l}\text { Correlación } \\
\text { de Pearson }\end{array}$ & ,577 & ,660 & 1 & 0.092 & -0.073 & 0.047 \\
\hline & $\begin{array}{l}\text { Sig. } \\
\text { (bilateral) }\end{array}$ & 0.000 & 0.000 & & 0.387 & 0.496 & 0.663 \\
\hline & $\mathrm{N}$ & 90 & 90 & 90 & 90 & 90 & 90 \\
\hline \multirow[t]{3}{*}{$\begin{array}{l}\text { G universidad } \\
\text { jefes }\end{array}$} & $\begin{array}{l}\text { Correlación } \\
\text { de Pearson }\end{array}$ & 0.093 & 0.028 & 0.092 & 1 & ,309 & 0.163 \\
\hline & $\begin{array}{l}\text { Sig. } \\
\text { (bilateral) }\end{array}$ & 0.382 & 0.793 & 0.387 & & 0.003 & 0.126 \\
\hline & $\mathrm{N}$ & 90 & 90 & 90 & 90 & 90 & 90 \\
\hline \multirow[t]{3}{*}{ G trabajo jefes } & $\begin{array}{l}\text { Correlación } \\
\text { de Pearson }\end{array}$ & 0.055 & 0.046 & -0.073 & ,309 & 1 &, 342 \\
\hline & $\begin{array}{l}\text { Sig. } \\
\text { (bilateral) }\end{array}$ & 0.605 & 0.670 & 0.496 & 0.003 & & 0.001 \\
\hline & $\mathrm{N}$ & 90 & 90 & 90 & 90 & 90 & 90 \\
\hline \multirow[t]{3}{*}{$\begin{array}{l}\text { G profesión } \\
\text { jefes }\end{array}$} & $\begin{array}{l}\text { Correlación } \\
\text { de Pearson }\end{array}$ & -0.033 & 0.118 & 0.047 & 0.163 &, 342 & 1 \\
\hline & $\begin{array}{l}\text { Sig. } \\
\text { (bilateral) }\end{array}$ & 0.756 & 0.266 & 0.663 & 0.126 & 0.001 & \\
\hline & $\mathrm{N}$ & 90 & 90 & 90 & 90 & 90 & 90 \\
\hline
\end{tabular}

Fuente: cuestionario 2019

El contador debe tener competencias para los negocios, aplicabilidad de leyes para funcionamiento y regulación de los mismos, los valores de evaluación de la competencia para los egresados muestra una significancia alta de 1, para universidad, 0.540 relación media para el trabajo y 0.577 también relación media para el futuro profesional, pero no es significativa para el mercado laboral (valores de 0.382, $0.670 \mathrm{y}$ $0.663)$.

Tabla 25.

Correlaciones mediante el Coeficiente de Pearson

\begin{tabular}{|c|c|c|c|c|c|c|c|}
\hline & & $\begin{array}{l}\text { H universidad } \\
\text { egresados }\end{array}$ & $\begin{array}{l}\text { H trabajo } \\
\text { egresados }\end{array}$ & $\begin{array}{l}\text { H profesión } \\
\text { egresados }\end{array}$ & $\begin{array}{l}\text { H universidad } \\
\text { jefes }\end{array}$ & $\begin{array}{l}\mathrm{H} \text { trabajo } \\
\text { jefes }\end{array}$ & $\begin{array}{l}\text { H profesión } \\
\text { jefes }\end{array}$ \\
\hline \multirow{3}{*}{$\begin{array}{l}\mathrm{H} \\
\text { universidad } \\
\text { egresados }\end{array}$} & $\begin{array}{l}\text { Correlación } \\
\text { de Pearson }\end{array}$ & 1 & ,611 & ,568 & 0.069 & -0.071 & 0.005 \\
\hline & $\begin{array}{l}\text { Sig. } \\
\text { (bilateral) }\end{array}$ & & 0.000 & 0.000 & 0.521 & 0.507 & 0.960 \\
\hline & $\mathrm{N}$ & 90 & 90 & 90 & 90 & 90 & 90 \\
\hline \multirow[t]{3}{*}{$\begin{array}{l}\mathrm{H} \text { trabajo } \\
\text { egresados }\end{array}$} & $\begin{array}{l}\text { Correlación } \\
\text { de Pearson }\end{array}$ & 611 & 1 & ,632 & 0.068 & -0.169 & -0.153 \\
\hline & $\begin{array}{l}\text { Sig. } \\
\text { (bilateral) }\end{array}$ & 0.000 & & 0.000 & 0.524 & 0.112 & 0.151 \\
\hline & $\mathrm{N}$ & 90 & 90 & 90 & 90 & 90 & 90 \\
\hline \multirow[t]{3}{*}{$\begin{array}{l}\text { H profesión } \\
\text { egresados }\end{array}$} & $\begin{array}{l}\text { Correlación } \\
\text { de Pearson }\end{array}$ &, 568 &, 632 & 1 & 0.142 & -0.196 & -0.035 \\
\hline & $\begin{array}{l}\text { Sig. } \\
\text { (bilateral) }\end{array}$ & 0.000 & 0.000 & & 0.181 & 0.064 & 0.741 \\
\hline & $\mathrm{N}$ & 90 & 90 & 90 & 90 & 90 & 90 \\
\hline \multirow{3}{*}{$\begin{array}{l}\mathrm{H} \\
\text { universidad } \\
\text { jefes }\end{array}$} & $\begin{array}{l}\text { Correlación } \\
\text { de Pearson }\end{array}$ & 0.069 & 0.068 & 0.142 & 1 &, 314 &, 244 \\
\hline & $\begin{array}{l}\text { Sig. } \\
\text { (bilateral) }\end{array}$ & 0.521 & 0.524 & 0.181 & & 0.003 & 0.021 \\
\hline & $\mathrm{N}$ & 90 & 90 & 90 & 90 & 90 & 90 \\
\hline $\begin{array}{l}\text { H trabajo } \\
\text { jefes }\end{array}$ & $\begin{array}{l}\text { Correlación } \\
\text { de Pearson }\end{array}$ & -0.071 & -0.169 & -0.196 &, 314 & 1 &, 435 \\
\hline
\end{tabular}




\begin{tabular}{|c|c|c|c|c|c|c|c|}
\hline \multirow{5}{*}{$\begin{array}{l}\text { H profesión } \\
\text { jefes }\end{array}$} & $\begin{array}{l}\text { Sig. } \\
\text { (bilateral) }\end{array}$ & 0.507 & 0.112 & 0.064 & 0.003 & & 0.000 \\
\hline & $\mathrm{N}$ & 90 & 90 & 90 & 90 & 90 & 90 \\
\hline & $\begin{array}{l}\text { Correlación } \\
\text { de Pearson }\end{array}$ & 0.005 & -0.153 & -0.035 & ,244 & ,435 & 1 \\
\hline & $\begin{array}{l}\text { Sig. } \\
\text { (bilateral) }\end{array}$ & 0.960 & 0.151 & 0.741 & 0.021 & 0.000 & \\
\hline & $\mathrm{N}$ & 90 & 90 & 90 & 90 & 90 & 90 \\
\hline
\end{tabular}

Fuente: cuestionario 2019

El Contador debe tener competencias para evaluar la empresa financiera y económicamente (Linares y Suárez, 2017). Sin embargo, los egresados asumen haber desarrollado la competencia necesaria en economía pero no es compatible con la evaluación de los jefes; la significancia bilateral de jefes para las competencias obtenidas en la universidad es de: 0.521 , para el trabajo es de 0.112 y para la profesión es de 0.741 .

Tabla 26.

Correlaciones mediante el Coeficiente de Pearson

\begin{tabular}{|c|c|c|c|c|c|c|c|}
\hline & & $\begin{array}{l}\text { I universidad } \\
\text { egresados }\end{array}$ & $\begin{array}{l}\text { I trabajo } \\
\text { egresados }\end{array}$ & $\begin{array}{l}\text { I profesión } \\
\text { egresados }\end{array}$ & $\begin{array}{l}\text { I universidad } \\
\text { jefes }\end{array}$ & $\begin{array}{l}\text { I trabajo } \\
\text { jefes }\end{array}$ & $\begin{array}{l}\text { I profesión } \\
\text { jefes }\end{array}$ \\
\hline \multirow[t]{3}{*}{$\begin{array}{l}\text { I universidad } \\
\text { egresados }\end{array}$} & $\begin{array}{l}\text { Correlación } \\
\text { de Pearson }\end{array}$ & 1 &, 521 &, 513 & 0.071 & 0.101 & -0.015 \\
\hline & $\begin{array}{l}\text { Sig. } \\
\text { (bilateral) }\end{array}$ & & 0.000 & 0.000 & 0.503 & 0.343 & 0.885 \\
\hline & $\mathrm{N}$ & 90 & 90 & 90 & 90 & 90 & 90 \\
\hline \multirow[t]{3}{*}{$\begin{array}{l}\text { I trabajo } \\
\text { egresados }\end{array}$} & $\begin{array}{l}\text { Correlación } \\
\text { de Pearson }\end{array}$ &, 521 & 1 & ,676 & 0.012 & 0.019 & -0.050 \\
\hline & $\begin{array}{l}\text { Sig. } \\
\text { (bilateral) }\end{array}$ & 0.000 & & 0.000 & 0.912 & 0.860 & 0.637 \\
\hline & $\mathrm{N}$ & 90 & 90 & 90 & 90 & 90 & 90 \\
\hline \multirow[t]{3}{*}{$\begin{array}{l}\text { I profesión } \\
\text { egresados }\end{array}$} & $\begin{array}{l}\text { Correlación } \\
\text { de Pearson }\end{array}$ &, 513 & ,676 & 1 & 0.101 & -0.110 & -0.112 \\
\hline & $\begin{array}{l}\text { Sig. } \\
\text { (bilateral) }\end{array}$ & 0.000 & 0.000 & & 0.344 & 0.302 & 0.294 \\
\hline & $\mathrm{N}$ & 90 & 90 & 90 & 90 & 90 & 90 \\
\hline \multirow[t]{3}{*}{$\begin{array}{l}\text { I universidad } \\
\text { jefes }\end{array}$} & $\begin{array}{l}\text { Correlación } \\
\text { de Pearson }\end{array}$ & 0.071 & 0.012 & 0.101 & 1 & ,384 & 0.046 \\
\hline & $\begin{array}{l}\text { Sig. } \\
\text { (bilateral) }\end{array}$ & 0.503 & 0.912 & 0.344 & & 0.000 & 0.665 \\
\hline & $\mathrm{N}$ & 90 & 90 & 90 & 90 & 90 & 90 \\
\hline \multirow[t]{3}{*}{$\begin{array}{l}\text { I trabajo } \\
\text { jefes }\end{array}$} & $\begin{array}{l}\text { Correlación } \\
\text { de Pearson }\end{array}$ & 0.101 & 0.019 & -0.110 &, 384 & 1 & ,446 \\
\hline & $\begin{array}{l}\text { Sig. } \\
\text { (bilateral) }\end{array}$ & 0.343 & 0.860 & 0.302 & 0.000 & & 0.000 \\
\hline & $\mathrm{N}$ & 90 & 90 & 90 & 90 & 90 & 90 \\
\hline \multirow[t]{3}{*}{$\begin{array}{l}\text { I profesión } \\
\text { jefes }\end{array}$} & $\begin{array}{l}\text { Correlación } \\
\text { de Pearson }\end{array}$ & -0.015 & -0.050 & -0.112 & 0.046 & ,446 & 1 \\
\hline & $\begin{array}{l}\text { Sig. } \\
\text { (bilateral) }\end{array}$ & 0.885 & 0.637 & 0.294 & 0.665 & 0.000 & \\
\hline & $\mathrm{N}$ & 90 & 90 & 90 & 90 & 90 & 90 \\
\hline
\end{tabular}

Fuente: cuestionario 2019. 
La estrategia de negocios y de gestión necesita de las competencias del Contador para desarrollar una empresa competitiva de un país insertándola en la modernidad (Rodríguez et al. 2012), pese a que la competencia necesaria para su trabajo ahora, en el futuro y la forma desarrollada en la universidad es significativa, no lo es en la evaluación de los jefes para las competencias desarrolladas (en la universidad $0.503>$ 0.05) (para el trabajo es de $0.860>0.05$ ) (útiles en la profesión $0.294>0.05$ ). Los fenómenos que hoy enfrenta la humanidad (globalización, conocimiento, procesos sociales y económicos) conllevan a implementar un modelo educativo por competencias (López, 2019). En función de ello el modelo de investigación a utilizar es:

\section{MODELO GRÁFICO DE INVESTIGACIÓN}

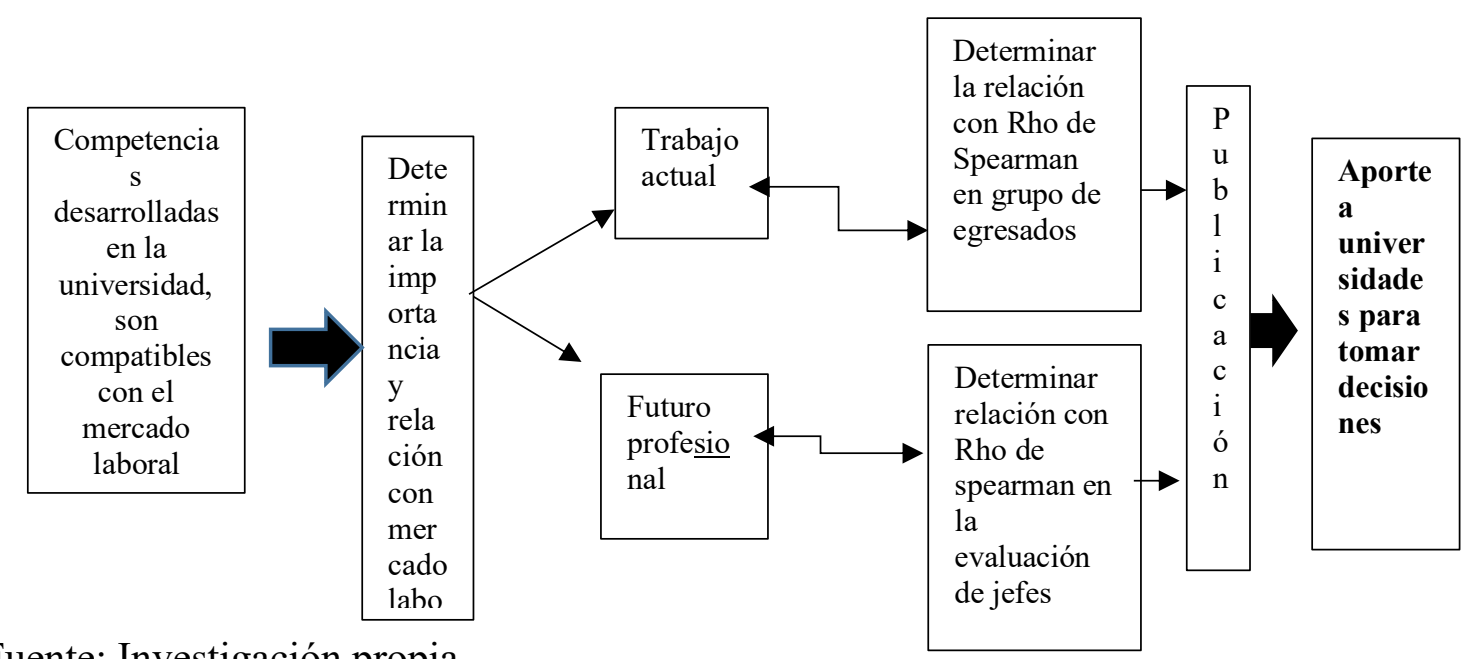

Fuente: Investigación propia.

\section{Conclusiones}

No existe relación entre empleabilidad y competencias desarrolladas en los egresados de Contabilidad de la Universidad Nacional de Cajamarca-Sede Chota, la significancia bilateral con el Rho de Spearman tiene un valor de $0.887>0.05$.

De las 34 secciones evaluadas, solo el 44\% tienen significancia estadística entre lo evaluado por los egresados y los jefes de los mismos; lo que significa que del 100\% de ítems desarrollados en la universidad, el 56\% no son compatibles con el empleo. El 12\% de ítems correspondientes a competencias específicas no tienen significancia estadística, lo que demuestra que no hay coherencia con lo expresado por el IFAC con lo desarrollado en el profesional de Contabilidad de la Universidad Nacional de Cajamarca, sede Chota. 
Con el Rho de Spearman se vio que las competencias generales no tienen significancia estadística (valor de 0.0891), tampoco las competencias usadas en el trabajo (valor de 0.999), las necesarias para la profesión en el futuro 0.877. Del mismo modo, las competencias para la empleabilidad no son significativas, su valor es 0.887 . El valor de significancia estadística de las competencias específicas no es significativa para los jefes, pero sí para los egresados. De las competencias evaluadas, según egresados, 58 se desarrollaron en la universidad, pero para los empleadores, no tuvieron el nivel deseado, y no fueron desarrolladas en absoluto competencias generales. El grado de empleabilidad de los egresados es bajo y la variable empleabilidad que tiene un coeficiente de 0.015 .

Referencias bibliográficas

Aguilar, A. (2 013). Educación superior y desarrollo en América Latina: un vínculo en debate. Buenos Aires, Argentina: CLACSO.

Castañeda, M. L. (2017). Aplicación de las normas internacionales de educacion para profesionales de la competitivad. Bogotá.

Centro de Investigación para el Desarrollo (2014). México.

http://cidac.org/esp/uploads/1/encuesta_competencias_profesionales_270214.pdf.

Federación Internacional de Contadores y Consejo de Normas Internacionales de Formación en Contaduría (2008). Manual de los procedimientos Internacionales de formación.

Gobierno de los Estados Unidos de México. (2013). Plan Nacional de Desarrollo 2013 - 2018. México.

Hernández, R., Fernández, C., y Baptista, P. (2014). Metodología de la Investigación Científica. México: McGraw Hill. México.

Mimbredo, C., Pallares, S., Guil, R. (2016). Competencias Implicadas en la Empleabilidad: Una propuesta desde la idgualdad de género. Cielo. 